\title{
Effect of porous zeolite on temperature-dependent physical properties of polypropylene/octadecane (PP/OD) composite films
}

\author{
D. Kim ${ }^{1,2}$, S. Thanakkasaranee ${ }^{1}$, J. Seo ${ }^{1 *}$, S. B. Khan ${ }^{3}$ \\ ${ }^{1}$ Department of Packaging, Yonsei University, 1 Yonseidae-gil, Wonju, 26493 Gangwon-do, Korea \\ ${ }^{2}$ Department of Food Science, Rutgers University 65 Dudley Road, New Brunswick, 08901 New Jersey, \\ United State of America \\ ${ }^{3}$ Center of Excellence for Advanced Materials Research and Chemistry Department, King Abdulaziz University, \\ P.O. Box 80203, 21589 Jeddah, Saudi Arabia
}

Received 18 December 2017; accepted in revised form 28 February 2018

\begin{abstract}
Polymeric materials with temperature-dependent gas permeabilities using a phase change material are designed and their applicability as a packaging system investigated. Polypropylene/octadecane/zeolite (PP/OD/ZL) composite films were prepared via extrusion process. ZL was used as a filler to enhance the dispersion and interfacial interaction between the OD and the PP originating from different flowabilities during the extrusion process. (FTIR) and (WAXD) analyses showed that the incorporation of ZL increased the interfacial interaction between PP and OD, resultantly enhancing the thermal stability, mechanical properties, and the oxygen transmittance rate and mechanical properties after contact with food simulants and thermal treatment. When the temperature was elevated from 10 to $30^{\circ} \mathrm{C}$, oxygen and water vapor transmittance rate of the composite films increased sharply because of the influence of the OD content. It was surmised that temperaturedependent permeation jump caused by increasing of segmental mobility of OD phase and converting the crystalline structure to an amorphous one of OD phase in the composite films. However, the permeation jump in the composite films was weakened as the ZL content increased. These results are related to changes in the interfacial interaction and crystallinity in the composite films due to the addition of ZL.
\end{abstract}

Keywords: polymer composites, temperature-dependent permeabilities, physical properties, packaging applications

\section{Introduction}

Gas permeation through polymers occurs via a sorption-diffusion mechanism [1-5]. Various penetrants such as $\mathrm{O}_{2}$ and water vapors adsorb onto the upper surface of a polymer, diffuse through the polymer matrix, and desorb from the opposite surface, while gas permeation properties of a material are strongly dependent on its chemical structure and changes in the polymer morphology originating from the temperature variations $[1-3,5]$. During the last several decades, many different groups have conducted research studies on the permeability of various pene- trant molecules (such as $\mathrm{O}_{2}$ and water vapors) in polymers [3-5]. Among the studied materials, polymers characterized by temperature-dependent gas and water vapor permeability properties such as poly(alkyl acrylate) $[3,5]$, poly $(N$-isopropylacrylamide) [1], polyurethane [6, 7], low-density polyethylene/paraffin wax (LDPE/PW) composite films [2], and polypropylene/octadecane (PP/OD) composite films [8] are becoming increasingly important in packaging applications for agricultural products and medical devices. The quality of agricultural products strongly depends on atmospheric composi- 
tions, which are affected by variations of respiration rates, transpiration during storage, and distribution environments $[1,3,5]$. Thus, sterilization of medical devices is required to maintain their aseptic environments until they are ready to use, and their packaging materials must possess the ability to survive a sterilization process [9]. Therefore, chemical and physical properties of the packaging materials should be adjusted to provide optimal gas permeability properties for practical applications in various fields.

Phase change materials (PCMs) are materials that store and release heat energy during temperature-driven phase changes $[2,8,10-12]$. Among various PCMs, PW is readily available and possess desirable characteristics such as large latent heat storage capacity, chemical inertness and stability, and non-toxicity [2, 10-13]. For these reasons, PW-based materials have been investigated for energy storage applications and thermal protection systems [10-12]. Various research groups have studied polymer/PCM composites because of their ability to maintain shape stability during usage $[2,8,10,11]$. The polymer matrix is able to arrange PCM species in a compact form and minimize PCM leakage from the polymer even after melting. However, some issues related to the polymer/PCM composites still persist including PCM leakage from the polymer matrix at high PCM contents and poor thermal conductivity. To overcome these problems, some researchers modified the known polymer/PCM composites by adding inorganic fillers $[10,11]$. Mhike et al. [10] investigated LDPE/soft Fisher-Tropsch wax/graphite composite sheets prepared by compounding and hot press methods. Molefi et al. [11] studied LDPE/wax/Cu, linear low-density polyethylene (LLDPE)/wax/Cu, and high-density polyethylene (HDPE)/wax/Cu mixtures prepared by compounding and hot press methods. They found that the incorporated fillers apparently improved thermal stability, thermal conductivity, and mechanical properties of the manufactured polymer/PCM composites for thermal energy storage and thermal protection applications [10, 11].

In our previous researches, polymer/PCM composite films such as LDPE/PW and PP/OD composites were fabricated for food packaging and medical device packaging and sterilization applications, and their temperature-dependent permeation properties were explored as functions of the PCM content and temperature $[2,8]$. The melting temperature of $\mathrm{PW}$ varies from 5.5 to $90^{\circ} \mathrm{C}$ depending on the number of $\mathrm{C}$ atoms (C14-C50) in the chain, which can possibly allow the development of composite films with optimal gas permeability values relying in different operational temperature ranges. The studied composite films contained two different phases (the polymer and PCM ones), and the resulting transformation of the PCM species into a polymer matrix occurring near the PCM phase temperature can significantly affect the morphology of the entire polymer/PCM composite and effectively create passing channels for various penetrants in the polymer matrix $[2,8]$. However, it is difficult to uniformly disperse PCM molecules in a polymer matrix during extrusion due to different flowabilities of the polymer and PCM species originating from the corresponding difference in their molecular weights $[2,8]$. In addition, it is not sufficient to maintain strong interfacial interactions between the olefin polymers (such as $\mathrm{PE}$ and PP) and the PCM species, although the olefin polymers and PW have the same chemical structure, and their composite films form a continuous phase, which results in decreased thermal stability and deterioration of the film mechanical properties $[2,8]$.

To overcome these disadvantages of the polymer/ PCM composite films, the incorporation of porous inorganic materials may synergistically allow the flowability control and enhancement of interfacial interactions due to the penetration of the OD and PP species inside the pores during extrusion. In this study, we have used hydrophobic ZSM-5 zeolite (ZL) as filler for the PP/OD composite films since the PP and OD molecular chains can be accommodated inside the porous structure of ZL. In addition, the hydrophobic ZL is non-polar [14], which can effectively enhance its physical interaction with non-polar OD and PP molecules, resulting in improvement of composite film physical properties. Morphological structures, thermal properties, permeability values, and mechanical properties of the fabricated $\mathrm{PP} / \mathrm{OD} / \mathrm{ZL}$ composite films were thoroughly investigated as functions of the ZL content and temperature. To utilize the as-prepared composite films in food and medical device packaging and sterilization applications, it is critical to evaluate changes in stability, compatibility, and physical properties of the composite films caused by their exposure to high temperatures and different kinds of food $[15,16]$. For this purpose, we have evaluated $\mathrm{O}_{2}$ permeability values and mechanical properties of the composite films after their contact with various food simulants and thermal treatment 
according to the standards specified by Regulation (EC) No 1935/2004 [17] and Regulation (EU) No $10 / 2011$ [18].

\section{Experiments}

\subsection{Materials}

Homo PP resin was provided by Samsung Chemical Co., Ltd. (Seoul, Korea). It was characterized by a melt flow index of $1.5 \mathrm{~g} / 10 \mathrm{~min}$ (ASTM D1238), molecular weight of $250000-300000 \mathrm{~g} / \mathrm{mol}$, and density of $0.90 \mathrm{~g} / \mathrm{cm}^{3}$. As a PCM, OD with a density of $0.78 \mathrm{~g} / \mathrm{cm}^{3}$ and melting point of $26-29^{\circ} \mathrm{C}$ was purchased from Sigma Aldrich Co., Ltd. (Yongin, Korea). To enhance the dispersion and miscibility of organic PP and inorganic ZL, Fusabond ${ }^{\circledR}$ E588, a maleic anhydride-grafted-polyolefin compatibilizer, was purchased from Dupont Co. Ltd. (Seoul, Korea). As a porous filler, ZL (Hisiv3000) was acquired from Union Showa K.K. Co., Ltd. (Tokyo, Japan). As shown in Figure 1, the Brunauer-Emmett-Teller (BET) surface area and total pore volume of ZL are

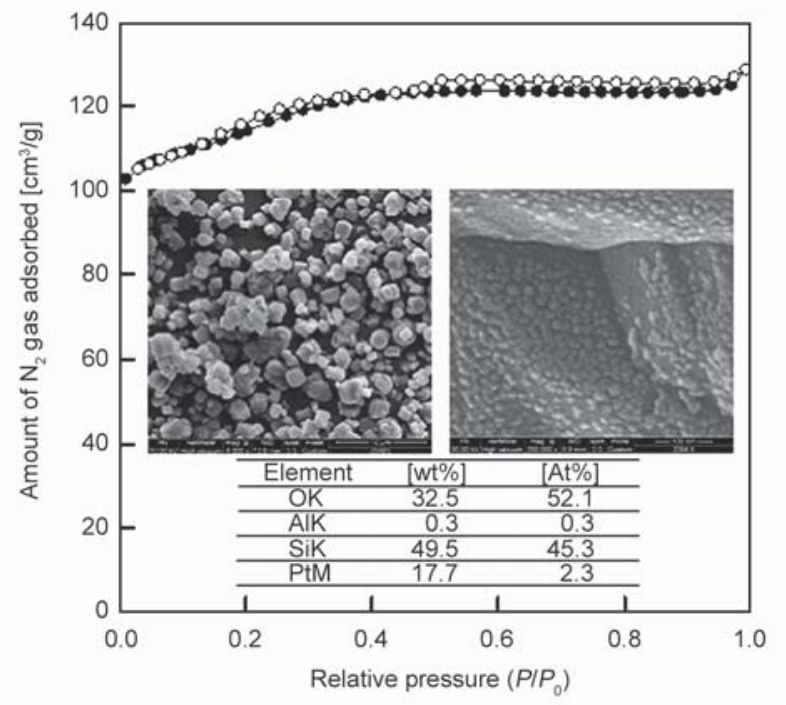

Figure 1. BET, SEM, and EDAX analyses of the hydrophobic ZSM-5 zeolite (ZL).
$385.0 \mathrm{~m}^{2} / \mathrm{g}$ and $0.2 \mathrm{~cm}^{3} / \mathrm{g}$, respectively. The ZL has a hexagonal plate-like crystal structure with its size in the range of 0.6 to $4.3 \mu \mathrm{m}$. According to the energy dispersive X-ray spectroscopy (EDAX) elemental analysis, the $\mathrm{Si} / \mathrm{Al}$ ratio in the obtained samples is 151 .

\subsection{Preparation of $\mathrm{PP} / \mathrm{OD} / \mathrm{ZL}$ composite films}

To remove residual volatile gases such as water vapor and residual compounds from the pores, $\mathrm{ZL}$ was first calcined in a muffle furnace at $300^{\circ} \mathrm{C}$ for $1 \mathrm{~h}$. Liquid OD obtained by heating the corresponding solid raw material to its melting temperature was mixed with the porous, layered structured ZL. According to the compositions listed in Table 1, six different compositions of the PP/OD/ZL composite pellets were prepared using a twin-screw extruder (BA-19, BauTech Co., Uijeongbu, Korea) for homogeneous mixing and dispersion. To remove water from the obtained pellets, the latter were dried at $80^{\circ} \mathrm{C}$ for $12 \mathrm{~h}$. From the as-prepared pellets, six different $\mathrm{PP} / \mathrm{OD} / \mathrm{ZL}$ composite films were prepared using the same extruder. The extruder temperature was set to $19{ }^{\circ} \mathrm{C}$ for the header, $190^{\circ} \mathrm{C}$ for zones $1-6$, and $120^{\circ} \mathrm{C}$ for the feed zone. The thickness of the composite films was maintained uniform at approximately $65 \pm 2 \mu \mathrm{m}$.

\section{Characterization}

\subsection{Morphology}

Adsorption-desorption properties were determined to analyze the BET specific surface area and total pore volume of ZL. $\mathrm{N}_{2}$ adsorption was studied using an ASAP 2010 Instrument (Micromeritics Co. Ltd., Norcross, GA, USA). To identify the dispersion of ZL and interfacial interaction between PP and ZL and $\mathrm{ZL}$ and $\mathrm{OD}$ in the PP/OD/ZL composite films, fractured scanning electron microscopy (SEM) images were obtained from a Quanta FEG250 scanning

Table 1. Compositions of the PP/OD composite films containing hydrophobic zeolites.

\begin{tabular}{|c|c|c|c|c|c|c|c|c|}
\hline \multirow[t]{2}{*}{ Sample code } & \multicolumn{4}{|c|}{$\begin{array}{c}\text { Compositions (weight) } \\
{[\mathrm{g}]}\end{array}$} & \multicolumn{4}{|c|}{$\begin{array}{c}\text { Compositions (volume) } \\
{\left[\mathrm{cm}^{3}\right]}\end{array}$} \\
\hline & $\mathbf{P P}$ & $\mathbf{E 5 8 8}^{*}$ & OD & $\mathbf{Z L}$ & PP & $\mathrm{E588}^{*}$ & OD & $\mathbf{Z L}$ \\
\hline $\mathrm{PP} / \mathrm{OD} / \mathrm{ZL} 0 \%$ & 97 & 3 & 20 & 0 & 78.8 & 2.5 & 18.7 & 0.0 \\
\hline $\mathrm{PP} / \mathrm{OD} / \mathrm{ZL} 3 \%$ & 97 & 3 & 20 & 3 & 76.4 & 2.4 & 18.2 & 3.0 \\
\hline $\mathrm{PP} / \mathrm{OD} / \mathrm{ZL} 5 \%$ & 97 & 3 & 20 & 5 & 74.9 & 2.3 & 17.8 & 5.0 \\
\hline $\mathrm{PP} / \mathrm{OD} / \mathrm{ZL} 10 \%$ & 97 & 3 & 20 & 10 & 71.4 & 2.2 & 17.0 & 9.4 \\
\hline $\mathrm{PP} / \mathrm{OD} / \mathrm{ZL} 20 \%$ & 97 & 3 & 20 & 20 & 65.2 & 2.0 & 15.5 & 17.3 \\
\hline $\mathrm{PP} / \mathrm{OD} / \mathrm{ZL} 30 \%$ & 97 & 3 & 20 & 30 & 59.9 & 1.9 & 14.3 & 23.9 \\
\hline
\end{tabular}

${ }^{*}$ Fusabond ${ }^{\circledR}$ E588 as a compatibilizer. 
electron microscope (FEI Co. Ltd., Hillsboro, Oregon, USA). Before examination, all the samples were coated with thin $\mathrm{Pt} / \mathrm{Pd}$ layers. To investigate the morphology of the composite films, wide-angle X-ray diffraction (WAXD) patterns were obtained using a D/MAX-2500 high-/low-temperature X-ray diffractometer (Rigaku Co. Ltd., Tokyo, Japan) equipped with a $\mathrm{Cu}-\mathrm{K} \alpha$ radiation source. The WAXD data were used to estimate the mean intermolecular distance ( $d$-spacing), crystallinity, and crystal sizes. The $d$ spacings of the PP/OD/ZL composite films were calculated using Equation (1):

$n \cdot \lambda=2 d \cdot \sin \theta$

where $n$ is the reflection order, $\lambda(=1.5406 \AA)$ is the wavelength of the $\mathrm{Cu}-\mathrm{K} \alpha \mathrm{X}$-ray radiation, $d$ is the mean intermolecular distance, and $\theta$ is the diffraction angle $[2,19,20]$. Subsequently, the percent crystallinity $\left(X_{\mathrm{c}, \text { WAXD }}\right)$ was evaluated from the WAXD data according to Equation (2):

$X_{\mathrm{c}, \mathrm{WAXD}}=\frac{\sum A_{\text {crist }}}{\sum A_{\text {crist }}+\sum A_{\text {amorp }}}$

where $A_{\text {cryst }}$ and $A_{\text {amorp }}$ are the integral areas of the crystalline and amorphous peaks for the composite films, respectively [2].

The densities of the composite films were measured using an AccuPyc II 1340 pycnometer (Micromeritics Instrument Co., Norcross, USA).

\subsection{Chemical structure}

To analyze the chemical and/or physical interactions between PP, OD, and ZL species in the composite films, Fourier transform infrared (FTIR) spectra were recorded using a Spectrum 65 spectrometer (PerkinElmer Co. Ltd., Waltham, Massachusetts, USA) in the range of 400 to $4000 \mathrm{~cm}^{-1}$ in the attenuated total reflection mode.

\subsection{Thermal properties}

To determine the thermal stability of the $\mathrm{ZL}$ and $\mathrm{PP} / \mathrm{OD} / \mathrm{ZL}$ composite films, thermogravimetric analysis (TGA) was performed on a 4000 TGA analyzer (PerkinElmer Co. Ltd., Waltham, Massachusetts, USA) at a heating rate of $10^{\circ} \mathrm{C} / \mathrm{min}$ from 50 to $700^{\circ} \mathrm{C}$ under $\mathrm{N}_{2}$ atmosphere. Furthermore, differential scanning calorimetry (DSC) was conducted using a Q10 calorimeter (TA Instruments Co. Ltd., New Castle Delaware, USA) under $\mathrm{N}_{2}$ atmosphere. The samples were heated from -40 to $200^{\circ} \mathrm{C}$ at a rate of $10^{\circ} \mathrm{C} / \mathrm{min}$. Percent crystallinity $\left(X_{\mathrm{c}, \mathrm{DSC}}\right)$ were calculated from the DSC data using Equation (3):

$X_{\mathrm{c}, \text { DSC }}=\frac{\Delta H_{\mathrm{m}}}{\Delta H_{\mathrm{m}}^{0}} \cdot 100$

where $\Delta H_{\mathrm{m}}$ is the melting enthalpy of the composite film, and $\Delta H_{\mathrm{m}}^{0}$ is the melting enthalpy of a fully crystalline PP sample $(209 \mathrm{~J} / \mathrm{g})[11,21]$.

\subsection{Oxygen and water vapor permeabilities}

OTRs for the PP/OD/ZL composite films were measured with an OTR $8001 \mathrm{O}_{2}$ permeability tester (Systech Instruments Co. Ltd., Johnsburg, Illinois, USA), while the corresponding WVTR values were evaluated by using a WVTR 8002 water vapor permeability tester (Systech Instruments Co. Ltd., Johnsburg, Illinois, USA). To investigate the effect of temperature on the obtained material permeability values, the OTR and WVTR tests were performed at 10, 15, $23,26.5,38$, and $48^{\circ} \mathrm{C}$.

\subsection{Contact angle and surface properties}

Contact angle and surface properties of the $\mathrm{PP} / \mathrm{OD} / \mathrm{ZL}$ composite films were investigated using a Phoenix 300 contact angle goniometer (SEO Co. Ltd., Suwon, Korea), while their surface free energies $\left(\gamma^{\mathrm{s}}\right)$ were measured via the Owens-Wendt geometric mean equation, which utilized the theory of adhesion between films and solvents [2, 19, 22]. Polar water $\left(\gamma^{\mathrm{S}}=72.8 \mathrm{~mJ} / \mathrm{m}^{2}, \gamma^{\mathrm{P}}=51.0 \mathrm{~mJ} / \mathrm{m}^{2}, \gamma^{\mathrm{D}}=21.8 \mathrm{~mJ} / \mathrm{m}^{2}\right)$ and nonpolar diiodomethane $\left(\gamma^{\mathrm{S}}=50.8 \mathrm{~mJ} / \mathrm{m}^{2}, \gamma^{\mathrm{P}}=\right.$ $50.4 \mathrm{~mJ} / \mathrm{m}^{2}, \gamma^{\mathrm{D}}=0.4 \mathrm{~mJ} / \mathrm{m}^{2}$ ) were employed during measurements $[2,19,22]$. Furthermore, the solubility parameter $\delta$, which serves as an indicator of the hydrophilicity or hydrophobicity of a polymer surface, was calculated by using Equation (4) [2, 19, 23, 24]:

$\delta=\left(e_{\mathrm{coh}}\right)^{1 / 2}$

where $e_{\text {coh }}$ is the cohesive energy density of the $\mathrm{PP} / \mathrm{OD} / \mathrm{ZL}$ composite films calculated using Equation $(5)[2,19,23,24]$ :

$\gamma^{\mathrm{s}}=0.75 \cdot\left(e_{\mathrm{coh}}\right)^{2 / 3}$

\subsection{Mechanical properties}

Mechanical properties of the PP/OD/ZL composite films were measured using a universal testing 
machine, QM 100T, equipped with a MC tester version 12.6.0 for analysis (Qmesys Co. Ltd., Kwangmyeong, Korea) according to ASTM D 638-14 (ASTM 2014) and D882-12 (ASTM 2012) specifications. The measurements were performed at a test speed of $500 \mathrm{~mm} / \mathrm{min}$ and cell load of $5 \mathrm{~kg}$ for specimens with $1 \mathrm{~cm}$ width and $8 \mathrm{~cm}$ length.

\subsection{Physical properties of the composite films exposed to food simulants and thermal treatment}

When the food application of the as-prepared composite films, it is considered contacts with waterbased, alcohol-based, acid-based, and lipid-based products $[15,16]$. Therefore, food contact simulations were performed in accordance with Regulation (EC) No 1935/2004 [17] and Regulation (EU) No 10/2011

[18] by using four different substances (distilled water at $40{ }^{\circ} \mathrm{C}$ for 10 day, $3 \% \mathrm{v} / \mathrm{v}$ acetic acid at $40^{\circ} \mathrm{C}$ for 10 day, $10 \% \mathrm{v} / \mathrm{v}$ ethanol at $40^{\circ} \mathrm{C}$ for 10 day, and iso-octane at $20^{\circ} \mathrm{C}$ for 2 day) [16-18]. $300 \mathrm{~mL}$ of a simulant was placed inside a $500 \mathrm{~mL}$ tray containing five film specimens with sizes of $12 \mathrm{~cm} \times 15 \mathrm{~cm}$ and subsequently covered. After the time of contact with the food simulants has passed, the specimens were removed from the tray, washed with distilled water, and dried inside an oven at $30^{\circ} \mathrm{C}$ for 2 day. Before the analysis, the composite films were stored at room temperature for 1 day, after which the effect of food simulants on their $\mathrm{O}_{2}$ permeability and mechanical properties was investigated.

In order to identify reproducibility of physical properties in the PP/OD/ZL composite films after exposed thermal treatment, the composite films were placed inside the drying oven at $50^{\circ} \mathrm{C}$ for 2 day and then transferred into a refrigerator with a temperature of $5^{\circ} \mathrm{C}$ for 2 day. After the thermal treatment, the effect on the $\mathrm{O}_{2}$ permeability and mechanical properties of the $\mathrm{PP} / \mathrm{OD} / \mathrm{ZL}$ composite films were analyzed.

\section{Results and discussion}

\subsection{Preparation of the PP/OD/ZL composite films}

The chemical structures of PP, OD, and ZL in the asprepared composite films as well as their interfacial interactions were analyzed by FTIR spectroscopy. As shown in Figure 2, ZL exhibits several characteristic peaks $[25,26]$ : asymmetric stretching vibrations of the external linkages between $\mathrm{TO}_{4}$ tetrahedra $(\mathrm{T}=$ $\mathrm{Si}$ or $\mathrm{Al}$ ) at $1226 \mathrm{~cm}^{-1}$, asymmetric and symmetric stretching vibrations of $\mathrm{T}-\mathrm{O}-\mathrm{T}$ at 1066 and $800 \mathrm{~cm}^{-1}$, respectively, vibrations at $544 \mathrm{~cm}^{-1}$ assigned to a pentasil structure consisting of five membered rings and $\mathrm{T}-\mathrm{O}$ bending vibrations of the $\mathrm{SiO}_{4}$ and $\mathrm{AlO}_{4}$ internal tetrahedra at $428 \mathrm{~cm}^{-1}$. In these rings, the vertices contained either $\mathrm{Si}$ or $\mathrm{Al}$ atoms linked through $\mathrm{O}$ atoms. The stretching vibration peaks of $\mathrm{C}=\mathrm{O}$ in Fusabond ${ }^{\circledR}$ E588 could be observed at $1712 \mathrm{~cm}^{-1}$ [27]. The obtained PP/OD/ZL composites exhibited characteristic peaks at the same positions as those observed for the PP/OD composite film without ZL [11, 28-30]: The $-\mathrm{CH}_{3}$ asymmetric stretching vibrations at $2950 \mathrm{~cm}^{-1}$, symmetric stretching vibrations of $-\mathrm{CH}_{2}-$ at 2838 and $2918 \mathrm{~cm}^{-1}$, that of $-\mathrm{CH}_{3}$ at $2868 \mathrm{~cm}^{-1},-\mathrm{CH}_{3}$ asymmetric deformation vibrations at $1454 \mathrm{~cm}^{-1}$ and $-\mathrm{CH}_{3}$ symmetric deformation vibrations at $1376 \mathrm{~cm}^{-1}$, carbon lattice pulsations at 1302 and $1256 \mathrm{~cm}^{-1}$, wagging and deformation vibrations of $-\mathrm{CH}_{3}$ and $-\mathrm{CH}_{2}-$ at $1166 \mathrm{~cm}^{-1}$, rocking vibrations of $-\mathrm{CH}_{3}$ at 998 and $974 \mathrm{~cm}^{-1}$ and those of $-\mathrm{CH}_{2}-$ at 842 and $808 \mathrm{~cm}^{-1}$, and in-plane rocking vibrations of $-\mathrm{CH}_{3}$ at $717 \mathrm{~cm}^{-1}$ originating from the presence of OD species. Further, the characteristic peaks of ZL gradually increased with an increase in the $\mathrm{ZL}$ content of the composite films; the peaks shifted from 1066 to $1102 \mathrm{~cm}^{-1}$ and 800 to $810 \mathrm{~cm}^{-1}$ for $\mathrm{T}-\mathrm{O}-\mathrm{T}$, from 544 to $538 \mathrm{~cm}^{-1}$ for the pentasil structure, and from 428 to $440 \mathrm{~cm}^{-1}$ for TO. In addition, the shift of carbonyl group $(\mathrm{C}=\mathrm{O})$ stretching of the maleic anhydride from 1712 to $1646 \mathrm{~cm}^{-1}$ could be observed, which might be related with physical interaction between Fusabond ${ }^{\circledR}$ E588, ZL, OD and PP.

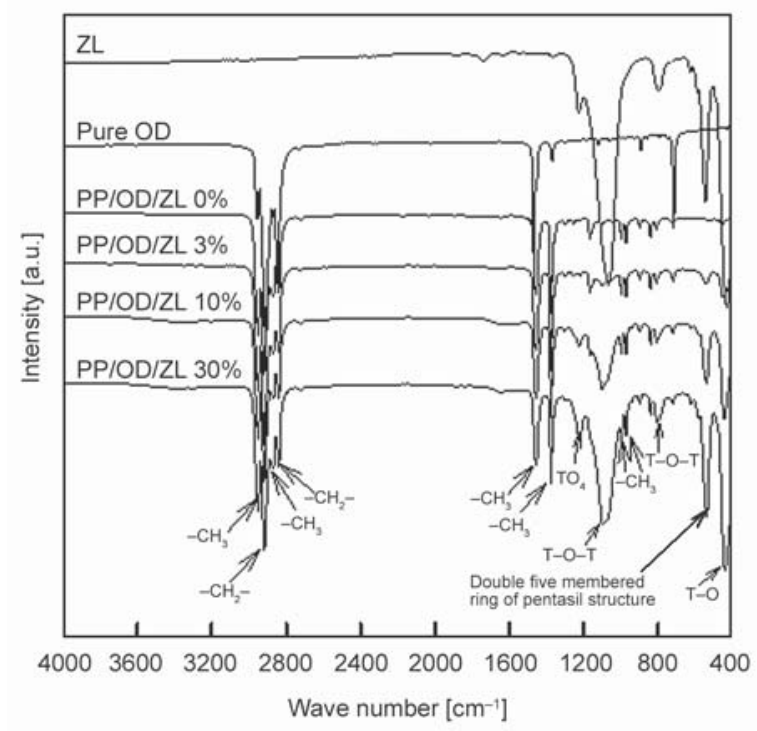

Figure 2. FTIR spectra of ZL, OD, and the PP/OD/ZL composite films. 
These shifts in the characteristic peaks indicate some changes in the chemical interaction between the three species in the composite films. As hydrophobic ZLs contain high amounts of $\mathrm{SiO}_{2} / \mathrm{Al}_{2} \mathrm{O}_{3}$, van der Waals or dipole-dipole interactions are usually involved in the adsorption process [14], which may strengthen the interfacial interaction between the OD or PP and ZL species in the composite films. These interactions may lead to improvements in the thermal stability and mechanical properties of the films.

\subsection{Morphology of the PP/OD/ZL composite films}

Analyzing the morphology of the organic/inorganic composites is valuable for assessing their thermal, mechanical, and gas permeation properties $[2,3,5$, $8,31]$. Figure 3 shows the WAXD patterns of $Z L$ and the PP/OD/ZL composite films, and the associated numerical values are summarized in Table 2 . The XRD pattern of ZL shows several sharp diffraction peaks at $2 \theta=7.9,8.7,14.7,23.0,23.9$ and $24.5^{\circ}$, which correspond to (011), (020), (031), (051), (303) and (313) planes of the ZSM-5 zeolite structure [14, $32,33]$.

In contrast, the $\mathrm{PP} / \mathrm{OD}$ composite film without $\mathrm{ZL}$ yielded an amorphous halo in the $2 \theta$ range of $15-25^{\circ}$ as well as four sharp diffraction peaks at $2 \theta=14.0$, $16.9,18.5$, and $21.5^{\circ}$, which are attributed to the (110), (040), (130), and (301) crystal planes of pure PP, respectively [34]. Furthermore, the XRD patterns of the five PP/OD/ZL composite films with 3-30 wt $\%$ ZL show several crystalline peaks that are almost identical to those observed for pure ZL in the $2 \theta$ range of $5-30^{\circ}$, with their intensities proportional to the ZL content $[14,32]$. As the ZL content increased from 0 to $30 \%$, the mean intermolecular distance related to the $2 \theta$ values of the (110), (040), (130), and (200) crystal planes of PP in the composite films slightly decreased in accordance with Bragg's law (see Table 2). The obtained WAXD results indicate that the incorporation of ZL slightly enhances the molecular ordering in the crystalline structure of the

Table 2. WAXD and density values for the PP/OD/ZL composite films.

\begin{tabular}{|c|c|c|c|c|c|c|c|c|c|c|}
\hline \multirow{3}{*}{ Sample code } & \multicolumn{8}{|c|}{ WAXD } & \multicolumn{2}{|c|}{ Density } \\
\hline & \multicolumn{2}{|c|}{ (110) } & \multicolumn{2}{|c|}{$(040)$} & \multicolumn{2}{|c|}{ (130) } & \multicolumn{2}{|c|}{ (301) } & \multirow[b]{2}{*}{$X_{\text {c. WAXD }}$} & \multirow[b]{2}{*}[\mathrm{g}/\mathrm{cm}^{3}]{} \\
\hline & $\begin{array}{l}2 \theta \\
{\left[^{\circ}\right]}\end{array}$ & $\begin{array}{c}d \text {-spacing } \\
[\AA]]\end{array}$ & $\begin{array}{l}\mathbf{2 \theta} \\
{\left[^{\circ}\right]}\end{array}$ & $\begin{array}{c}d \text {-spacing } \\
{[\AA]}\end{array}$ & $2 \theta$ & $\begin{array}{c}d \text {-spacing } \\
{[\AA]}\end{array}$ & $\begin{array}{l}2 \theta \\
{\left[^{\circ}\right]}\end{array}$ & $\begin{array}{c}d \text {-spacing } \\
{[\AA]}\end{array}$ & & \\
\hline $\mathrm{PP} / \mathrm{OD} / \mathrm{ZL} 0 \%$ & 14.01 & 6.32 & 16.82 & 5.27 & 18.44 & 4.81 & 21.58 & 4.12 & 31.8 & 0.92 \\
\hline PP/OD/ZL 3\% & 13.98 & 6.33 & 16.86 & 5.26 & 18.46 & 4.80 & 21.83 & 4.07 & 32.3 & 0.93 \\
\hline PP/OD/ZL 5\% & 14.02 & 6.31 & 16.90 & 5.24 & 18.51 & 4.79 & 21.70 & 4.09 & 33.7 & 0.93 \\
\hline $\mathrm{PP} / \mathrm{OD} / \mathrm{ZL} 10 \%$ & 14.01 & 6.32 & 16.86 & 5.26 & 18.49 & 4.80 & 21.81 & 4.07 & 34.3 & 0.95 \\
\hline PP/OD/ZL 20\% & 14.04 & 6.31 & 16.91 & 5.24 & 18.49 & 4.80 & 21.79 & 4.08 & 35.1 & 0.96 \\
\hline PP/OD/ZL 30\% & 14.05 & 6.30 & 16.92 & 5.24 & 18.52 & 4.79 & 21.98 & 4.04 & 37.8 & 1.00 \\
\hline
\end{tabular}
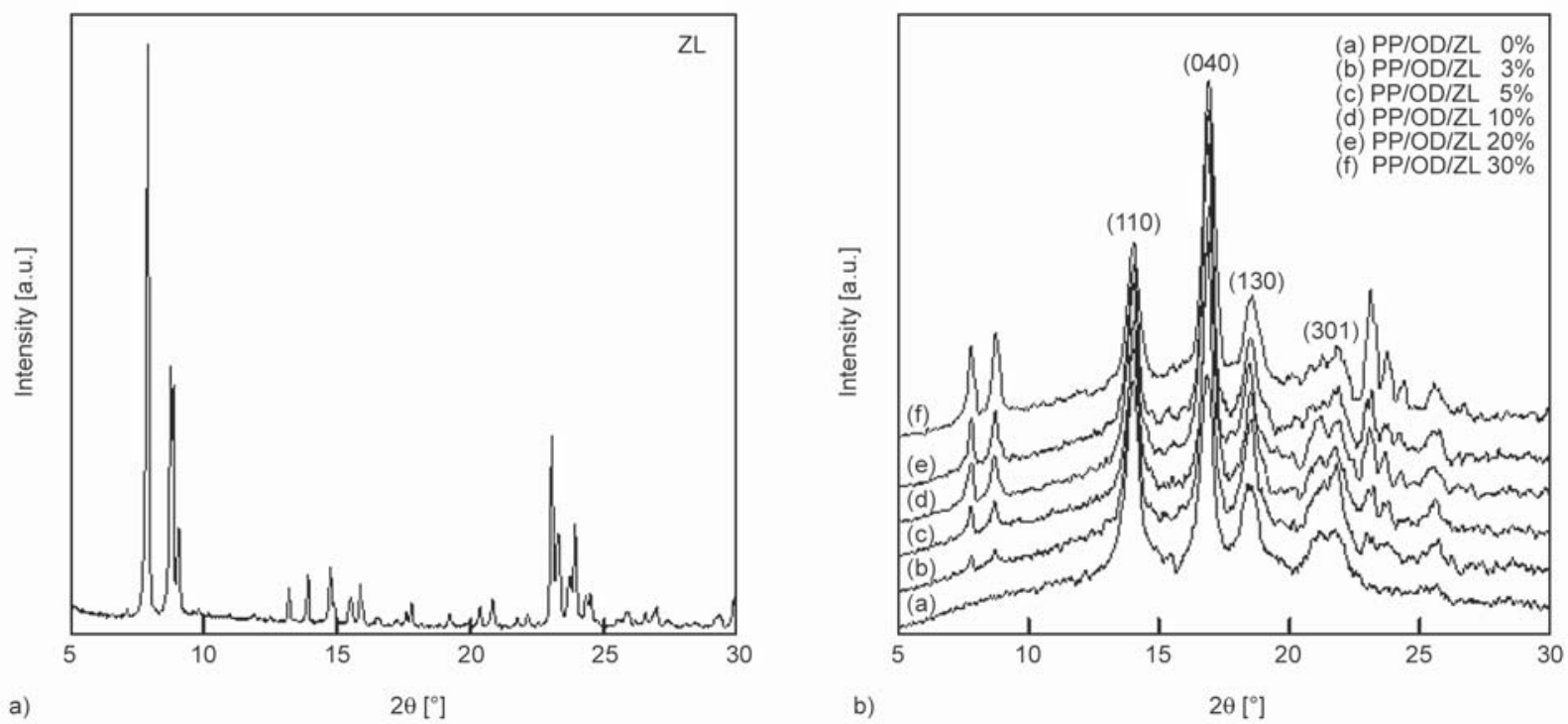

$2 \theta\left[^{\circ}\right]$

b)

$2 \theta\left[{ }^{\circ}\right]$

Figure 3. WAXD patterns for (a) ZL and (b) the PP/OD/ZL composite films. 
$\mathrm{PP} / \mathrm{OD} / \mathrm{ZL}$ composite film. Therefore, the percent crystallinity values for the five $\mathrm{PP} / \mathrm{OD} / \mathrm{ZL}$ composite films are higher than that for the PP/OD composite film without ZL.

The density of the composite films increased from 0.92 to $1.00 \mathrm{~g} / \mathrm{cm}^{3}$ with an increase in the ZL content, which might be possibly due to the enhanced interfacial interactions between PP and OD, as observed by FTIR measurements (see Figure 2 and Table 2). Although PP and OD have similar non-polar chemical structures, their interfacial interaction is not strong enough to yield a good dispersion, owing to the highly mismatched flowability related to different molecular weights [31]. An increase in the content of hydrophobic ZL with the porous non-polar structure was expected to decrease the flowability of the
PP/OD/ZL $0 \%$

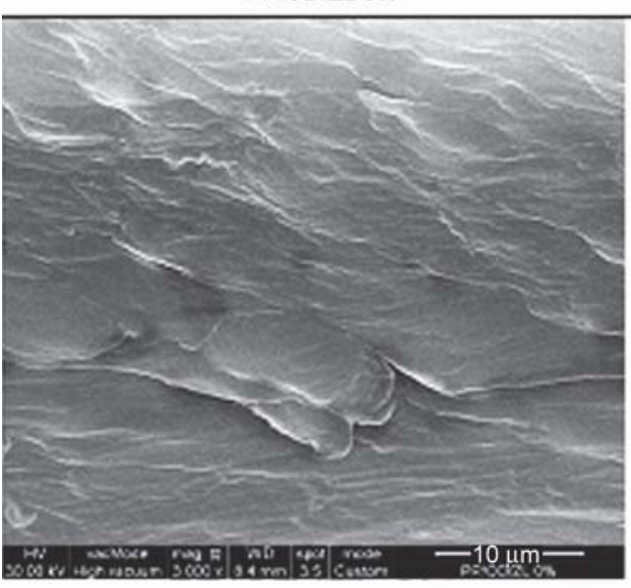

PP/OD/ZL 5\%

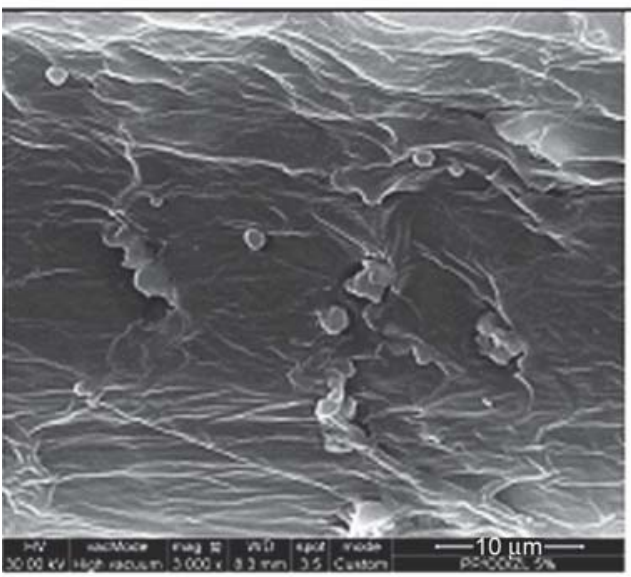

PP/OD/ZL 20\%

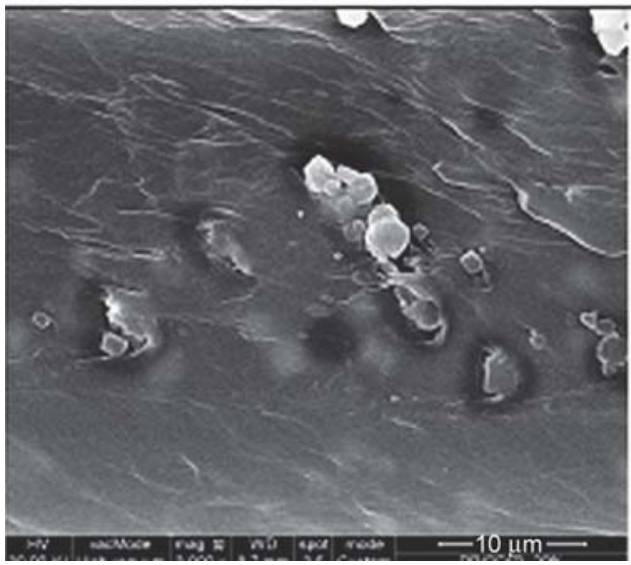

PP/OD/ZL 3\%

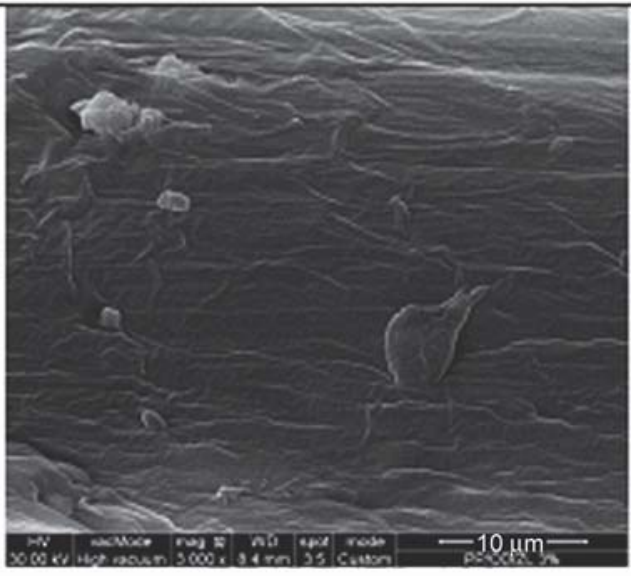

PP/OD/ZL $10 \%$

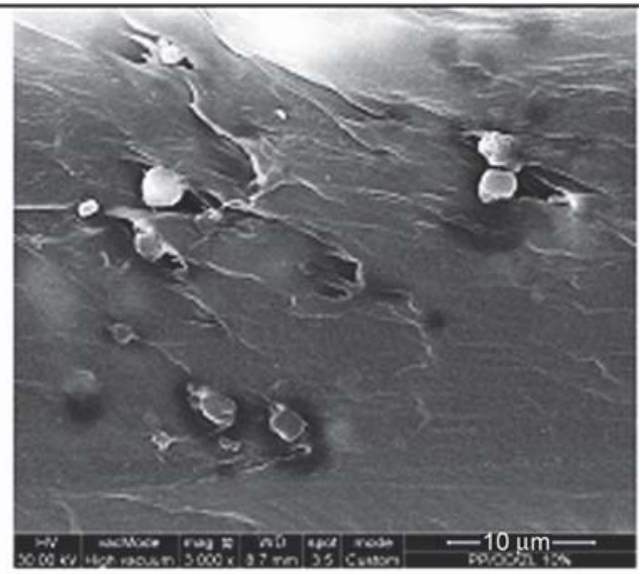

PP/OD/ZL $30 \%$

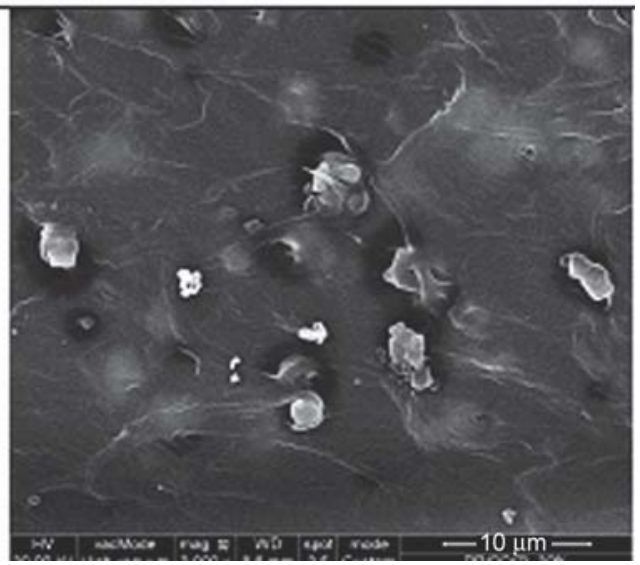

Figure 4. SEM images of the fractured surface in PP/OD/ZL composite films. 
low molecular weight $\mathrm{OD}$, matching the flowability of OD with that of PP and finally leading to a good dispersion of OD in PP.

To determine the dispersion state and interfacial interaction of the ZL particles in the PP/OD/ZL composite films, SEM analyses of the fractured surfaces of the PP/OD/ZL composite films were performed (Figure 4). Our previous study showed that the adhesion and interfacial interaction between non-polar OD and non-polar PP was maintained to some degree at a high OD content in the PP matrix [8]. Likewise, there were no cracks or voids on the fractured surface of the PP/OD composite film without ZL. As $\mathrm{ZL}$ with a relatively high $\mathrm{Si} / \mathrm{Al}$ ratio has a hydrophobic chemical structure, it may interact well with PP and OD [14]. Thus, this will prevent the production of defects such as inner cracks and voids originating from weak interfacial interaction between the different components of the composite films. In this study, ZL was observed to be well-embedded in PP/OD matrix as ascertained by SEM analyses of the fractured composite films. This indicates that ZL strongly interacts with PP and OD [35]. However, agglomeration of $\mathrm{ZL}$ in the $\mathrm{PP} / \mathrm{OD}$ matrix increased slightly with an increase in the ZL content. In our previous study, the different flowabilities of PP and OD originating from the difference in their molecular weights could have increased the phase separation of PP and OD, thereby significantly affecting the physical properties of the PP/OD/ZL composite films [8]. However, after the introduction of ZL into the PP/OD matrix, no discernible phase separation was observed. According to the FTIR, SEM, WAXD, and density measurement results, the interfacial interaction and crystallinity of the composite films were enhanced upon adding ZL. This might be because ZL aided in controlling the flowability of OD with respect to the PP phase.

\subsection{Thermal properties}

For many packaging applications, the polymeric material is required to possess high thermal stability to endure high-temperature treatments such as extrusion and injection molding, as well as the sterilization process [36, 37], while a strong interfacial interaction between the polymer and the additives may significantly affect the thermal properties [37]. As shown in Figure 5 and Table 3, all the composite films exhibit two-step degradation processes similar to those observed for PP/OD composite films without ZL, indicating that the ZL content did not significantly influence the thermal degradation characteristic of the composite films. In addition, the residual ZL content measured at $700^{\circ} \mathrm{C}$ is consistent with the corresponding theoretical ZL content, demonstrating that the ZL particles were successfully incorporated into the PP/OD matrix. The first degradation stage between 130 and $340^{\circ} \mathrm{C}$ is due to the decomposition of OD near its flash temperature $[38,39]$ or evaporation before the boiling temperature of $\operatorname{OD}[39,40]$ while the second degradation stage between 340 and $480^{\circ} \mathrm{C}$ results from the bond scission and chain transfer reactions of the PP trimers in pure PP [41, 42]. With increasing ZL content from 0 to $30 \%$, the decomposition temperature increased from 170.2 to $187.6^{\circ} \mathrm{C}$ for a $1 \mathrm{wt} \%$ decomposition $\left(T_{\mathrm{d} 1 \%}\right)$ and from 308.5 to $399.9^{\circ} \mathrm{C}$ for a $10 \mathrm{wt} \%$ decomposition $\left(T_{\mathrm{d} 10 \%}\right)$, respectively. Such enhancement of the thermal stability of the PP/OD/ZL composite films can be attributed to the structural changes originating from the interfacial interaction between the PP, OD, and ZL species. Based on the shift of the characteristic peaks of ZL identified by FTIR analysis, decrease of intermolecular mean distance of the crystal planes of PP calculated by Bragg's law, and good adhesion between ZL and PP/OD matrix observed by SEM analysis, presumably, the non-polar porous ZL particles strongly interact with the non-polar OD and PP species. These interfacial interactions and the ZL porous structure may restrict the chain mobility and thus enhance the thermal stability of the obtained composite films.

Phase transitions from the crystalline to amorphous structures produce significant changes in the physical

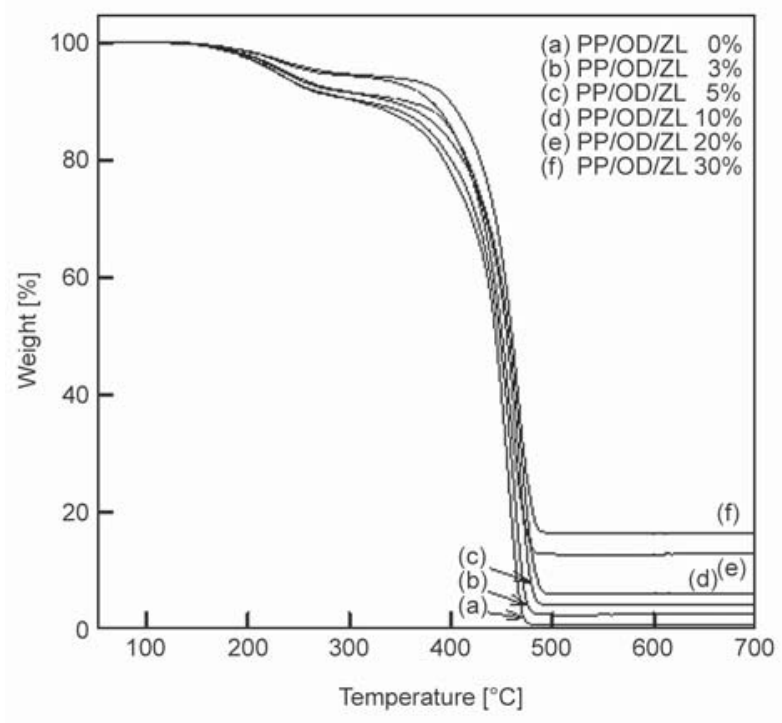

Figure 5. TGA curves of the PP/OD/ZL composite films. 
Table 3. Thermal properties of the PP/OD/ZL composite films.

\begin{tabular}{|c|c|c|c|c|c|c|c|c|c|c|c|c|c|c|}
\hline \multirow[b]{2}{*}{ Sample code } & \multicolumn{10}{|c|}{ DSC } & \multicolumn{4}{|c|}{ TGA } \\
\hline & $\begin{array}{l}T_{\mathrm{m} 1}{ }^{\mathrm{a}} \\
{\left[{ }^{\circ} \mathbf{C}\right]}\end{array}$ & $\begin{array}{l}T_{\mathrm{m} 2}{ }^{\mathbf{a}} \\
{\left[{ }^{\circ} \mathrm{C}\right]}\end{array}$ & $\begin{array}{c}\Delta H_{\mathrm{m} 1}{ }^{\mathrm{b}} \\
{[\mathrm{J} / \mathrm{g}]}\end{array}$ & $\begin{array}{c}\Delta H_{\mathrm{m} 2}{ }^{\mathrm{b}} \\
{[\mathrm{J} / \mathrm{g}]}\end{array}$ & $\begin{array}{c}\Delta H_{\text {total }}{ }^{\mathrm{c}} \\
{[\mathrm{J} / \mathrm{g}]}\end{array}$ & $\begin{array}{l}T_{\mathrm{c1}}{ }^{\mathrm{d}} \\
{\left[{ }^{\circ} \mathrm{C}\right]}\end{array}$ & $\begin{array}{l}T_{\mathrm{c} 2}{ }^{\mathrm{d}} \\
{\left[^{\circ} \mathrm{C}\right]}\end{array}$ & $\begin{array}{l}\Delta H_{\mathrm{cl}}{ }^{\mathrm{e}} \\
{[\mathrm{J} / \mathrm{g}]}\end{array}$ & $\begin{array}{c}\Delta \boldsymbol{H}_{\mathrm{c} 2}{ }^{\mathrm{e}} \\
{[\mathrm{J} / \mathrm{g}]}\end{array}$ & $X_{\mathrm{c}}^{\mathrm{f}}$ & $\begin{array}{c}T_{\mathrm{d}_{1 \% \%}}{ }^{\mathrm{g}} \\
{\left[{ }^{\circ} \mathbf{C}\right]}\end{array}$ & $\begin{array}{c}T_{\mathrm{d}_{3 \%}{ }^{\mathrm{g}}} \\
{\left[{ }^{\circ} \mathbf{C}\right]}\end{array}$ & $\begin{array}{c}T_{\mathrm{d}_{10 \%}{ }^{\mathrm{g}}} \\
{\left[{ }^{[0} \mathrm{C}\right]}\end{array}$ & {$[w t \%]^{h}$} \\
\hline PP/OD/ZL 0\% & 21.8 & 161.4 & 15.5 & 84.3 & 99.8 & 2.7 & 107.9 & 14.6 & 86.9 & 47.8 & 170.2 & 204.9 & 308.5 & 0.7 \\
\hline $\mathrm{PP} / \mathrm{OD} / \mathrm{ZL} 3 \%$ & 18.0 & 159.1 & 15.2 & 90.5 & 105.7 & 4.0 & 110.1 & 12.7 & 90.1 & 49.2 & 172.8 & 207.1 & 314.3 & 2.5 \\
\hline $\mathrm{PP} / \mathrm{OD} / \mathrm{ZL} 5 \%$ & 19.0 & 160.4 & 11.4 & 89.0 & 100.4 & 4.8 & 113.2 & 10.7 & 88.6 & 48.0 & 174.8 & 214.6 & 341.2 & 4.0 \\
\hline $\mathrm{PP} / \mathrm{OD} / \mathrm{ZL} 10 \%$ & 17.9 & 160.9 & 10.0 & 88.8 & 98.8 & 3.0 & 117.6 & 9.2 & 88.9 & 47.3 & 176.4 & 212.2 & 357.3 & 5.9 \\
\hline $\mathrm{PP} / \mathrm{OD} / \mathrm{ZL} 20 \%$ & 12.1 & 162.4 & 5.3 & 87.6 & 92.9 & -4.6 & 120.8 & 4.0 & 87.1 & 44.4 & 185.3 & 228.8 & 380.7 & 12.8 \\
\hline $\mathrm{PP} / \mathrm{OD} / \mathrm{ZL} 30 \%$ & 9.1 & 162.6 & 2.8 & 79.8 & 82.6 & -7.4 & 119.1 & 2.8 & 79.0 & 39.5 & 187.6 & 232.8 & 399.0 & 16.4 \\
\hline
\end{tabular}

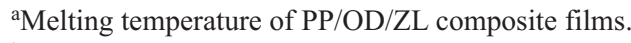

${ }^{b}$ Melting enthalpy of of PP/OD/ZL composite films.

${ }^{c}$ Total melting enthalpy of PP/OD/ZL composite films.

${ }^{\mathrm{d} C r y s t a l l i z a t i o n}$ temperature of PP/OD/ZL composite films.

${ }^{\mathrm{e}}$ Crystallization enthalpy of $\mathrm{PP} / \mathrm{OD} / \mathrm{ZL}$ composite films.

${ }^{\mathrm{f}}$ Crystallinity of PP/OD/ZL composite films by DSC analysis.

$\mathrm{g}_{1} 1,3$, and $10 \%$ decomposition temperature of $\mathrm{PP} / \mathrm{OD} / \mathrm{ZL}$ composite films.

${ }^{\text {h}}$ Weight residue in $\mathrm{PP} / \mathrm{OD} / \mathrm{ZL}$ composite films at $700^{\circ} \mathrm{C}$.

properties of the polymeric materials, such as $\mathrm{O}_{2}$ and water vapor permeabilities [1-3, 5-8]. To investigate possible phase transitions in the composite films, DSC analysis was conducted (Figure 6 and Table 3). The PP/OD composite film without ZL exhibited two endothermic peaks at 21.8 and $161.4^{\circ} \mathrm{C}$ during heating and two exothermic peaks at 2.7 and $107.9^{\circ} \mathrm{C}$ during cooling. The melting enthalpy $\left(\Delta H_{\mathrm{m}}\right)$ and crystallization enthalpy $\left(\Delta H_{\mathrm{c}}\right)$ of the PP/OD composite film without ZL are 15.5 and $84.3 \mathrm{~J} / \mathrm{g}$ for heating and 14.6 and $86.9 \mathrm{~J} / \mathrm{g}$ for cooling, respectively. The first peak is associated with the phase transition in the OD species, while the second peak is related to the phase transition originating from the PP melting $[11,21]$.

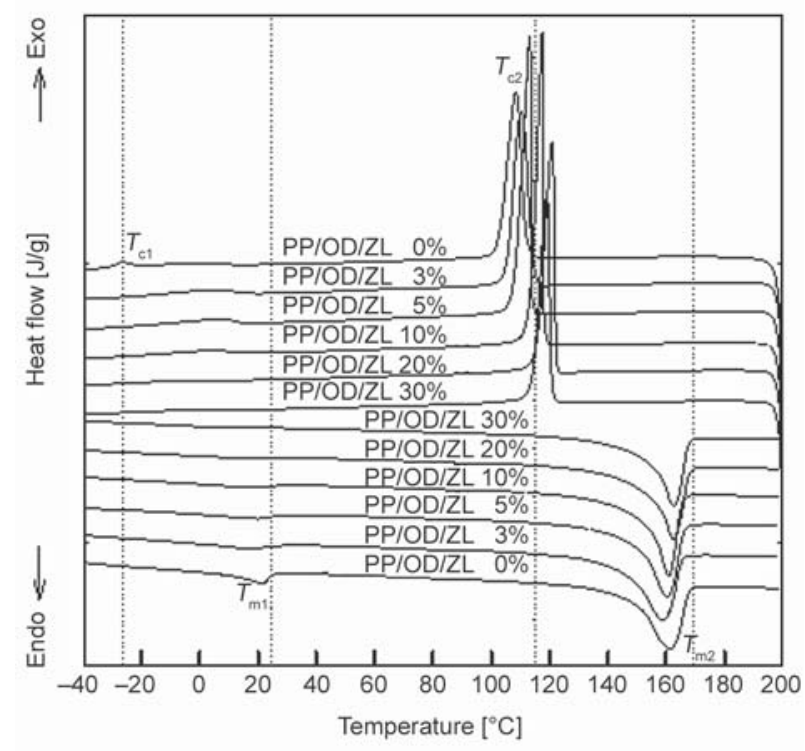

Figure 6. DSC curves of the PP/OD/ZL composite films.
The initial melting $\left(T_{\mathrm{m} 1}\right)$ and crystallization $\left(T_{\mathrm{cl}}\right)$ temperatures of the OD phases for the composite films decreased from 21.8 to $9.1^{\circ} \mathrm{C}$ and 2.7 to $-7.4^{\circ} \mathrm{C}$, respectively, whereas the $\Delta H_{\mathrm{m} 1}$ and $\Delta H_{\mathrm{c} 1}$ values of the OD crystalline phases (corresponding to the melting and crystallization temperatures, $T_{\mathrm{m} 1}$ and $T_{\mathrm{c} 1}$, respectively) decreased from 15.5 to $2.8 \mathrm{~J} / \mathrm{g}$ and from 14.6 to $2.8 \mathrm{~J} / \mathrm{g}$, respectively, with an increase in the $\mathrm{ZL}$ content from 0 to $30 \%$. As the ZL content increases, the OD fraction in the PP matrix decreases, resulting in a broad small DSC feature corresponding to the OD crystalline structure in the composite films. This indicates that decreased OD contents in the PP matrix produce fewer changes in the morphological structure of the composite films due to variations in the ZL content.

The presence and relative amount of ZL strongly affect the melting and crystallization behaviors of the PP phases in the composite films. Thus, the second melting $\left(T_{\mathrm{m} 2}\right)$ and crystallization $\left(T_{\mathrm{c} 2}\right)$ temperatures increased from 161.4 to $162.6^{\circ} \mathrm{C}$ and from 107.9 to $119.1^{\circ} \mathrm{C}$, respectively, with an increase in the ZL content from 0 to $30 \%$, while the corresponding $\Delta H_{\mathrm{m} 2}$ and $\Delta H_{\mathrm{c} 2}$ values for the PP crystalline phases increased only slightly, indicating that ZL acts as a nucleating agent for the PP crystalline phases in the PP/ OD/ZL composite films. However, the PP crystalline fractions of the PP/OD/ZL composite films significantly decreased with an increase in the ZL content to $30 \%$ because high ZL contents inhibit the formation of a PP crystalline phase [11].

The total $\Delta H_{\mathrm{m}}$ and $\Delta H_{\mathrm{c}}$ values for the PP/OD/ZL composite films slightly increased with an increase 
in the ZL content up to 5\% and then significantly decreased. The obtained results are inconsistent with the WAXD data described earlier and may be explained by the complexity of PP, OD, and ZL compositions in the composite films. First, the fraction of the ZL crystalline structure in the composite films increases upon the introduction of ZL; however, it could not be identified by the DSC analysis due to the unchanged ZL morphology during melting or crystallization. In addition, the crystalline structures corresponding to the OD and PP phases in the composite films were differently affected by the increase in the ZL content. Overall, the presence of OD alters the morphological structure of the PP matrix. This can possibly change their morphologies depending on the phase change temperature originating from the OD addition. After introducing ZL with the non-polar and porous structure into the composite films, however, ZL strongly interacts with the low molecular weight OD and thus restricts its chain mobility. As a result, the temperature-dependent morphological changes in the composite films originating from the OD addition become less intense upon the addition of ZL.

\subsection{Oxygen and water vapor permeability}

Figure 7 shows the oxygen and water vapor permeability values for the PP/OD/ZL composite films with corresponding DSC analysis. In our previous study, the magnitudes of oxygen and water vapor permeation jumps started to increase between 10 and $30^{\circ} \mathrm{C}$ depending on the OD content in PP [8]. The OTR and WVTR for the PP/OD composite film with $0 \% \mathrm{ZL}$ increased from 7739 to $34235 \mathrm{cc} / \mathrm{m}^{2}$.day and from 3.1 to $33.1 \mathrm{~g} / \mathrm{m}^{2}$ day, respectively, with an increase in temperature from 10 to $48^{\circ} \mathrm{C}$. However, OTR and WVTR values of PP/OD/ZL $0 \%$ composite films were different from them of PP/OD 20\% composite films [8]. This may due to be modified the surface properties in the $\mathrm{PP} / \mathrm{OD} 20 \%$ matrix by adding the Fusabond ${ }^{\mathbb{R}}$ E588 with amphiphilic property.

The OTRs for the PP/OD/ZL composite films also increased from 7056 to $31945 \mathrm{cc} / \mathrm{m}^{2}$.day, from 6306 to $28524 \mathrm{cc} / \mathrm{m}^{2} \cdot$ day, from 5104 to $22518 \mathrm{cc} / \mathrm{m}^{2} \cdot$ day, from 3749 to $20376 \mathrm{cc} / \mathrm{m}^{2}$.day, and from 2293 to $16204 \mathrm{cc} / \mathrm{m}^{2}$.day. The trends of obtained WVTR data for the PP/OD/ZL composite films were similar to the OTR ones, increasing from 1.7 to $29.4 \mathrm{~g} / \mathrm{m}^{2}$.day, from 1.6 to $29.1 \mathrm{~g} / \mathrm{m}^{2}$.day, from 1.5 to $28.8 \mathrm{~g} / \mathrm{m}^{2}$.day, from 1.3 to $27.8 \mathrm{~g} / \mathrm{m}^{2}$.day, and from 1.0 to $25.6 \mathrm{~g} / \mathrm{m}^{2}$.day with a temperature increase from 10 to $48^{\circ} \mathrm{C}$. Although the OTRs and WVTRs for the composite films increased with increasing temperature, the permeation jumps decreased at higher ZL contents. To identify the $\mathrm{O}_{2}$ and water vapor permeation behavior of $\mathrm{PP} /$ $\mathrm{OD} / \mathrm{ZL}$ composite films as a function of temperature, we used the Arrhenius equation, as described by Equation (6):

$\ln P=\ln P_{0}-\frac{E_{\mathrm{a}}}{R T}$

where $P\left(\mathrm{O}_{2}\right.$ and water vapor: $\left.\mathrm{mols} \cdot \mathrm{m} / \mathrm{m}^{2} \cdot \mathrm{s} \cdot \mathrm{Pa}\right)$ is the permeability of the composite film, $P_{0}$ represents the permeability coefficient of composite films, $E_{\mathrm{a}}[\mathrm{J} / \mathrm{mol}]$ is the activation energy for penetrants, $R[\mathrm{~J} /(\mathrm{mol} \cdot \mathrm{K})]$ is an universal gas constant, and $T[\mathrm{~K}]$ explains absolute temperature $[3,28,43]$.

We chose the reference temperature, $26.5^{\circ} \mathrm{C}$, to compare intermediate state and completely melting state
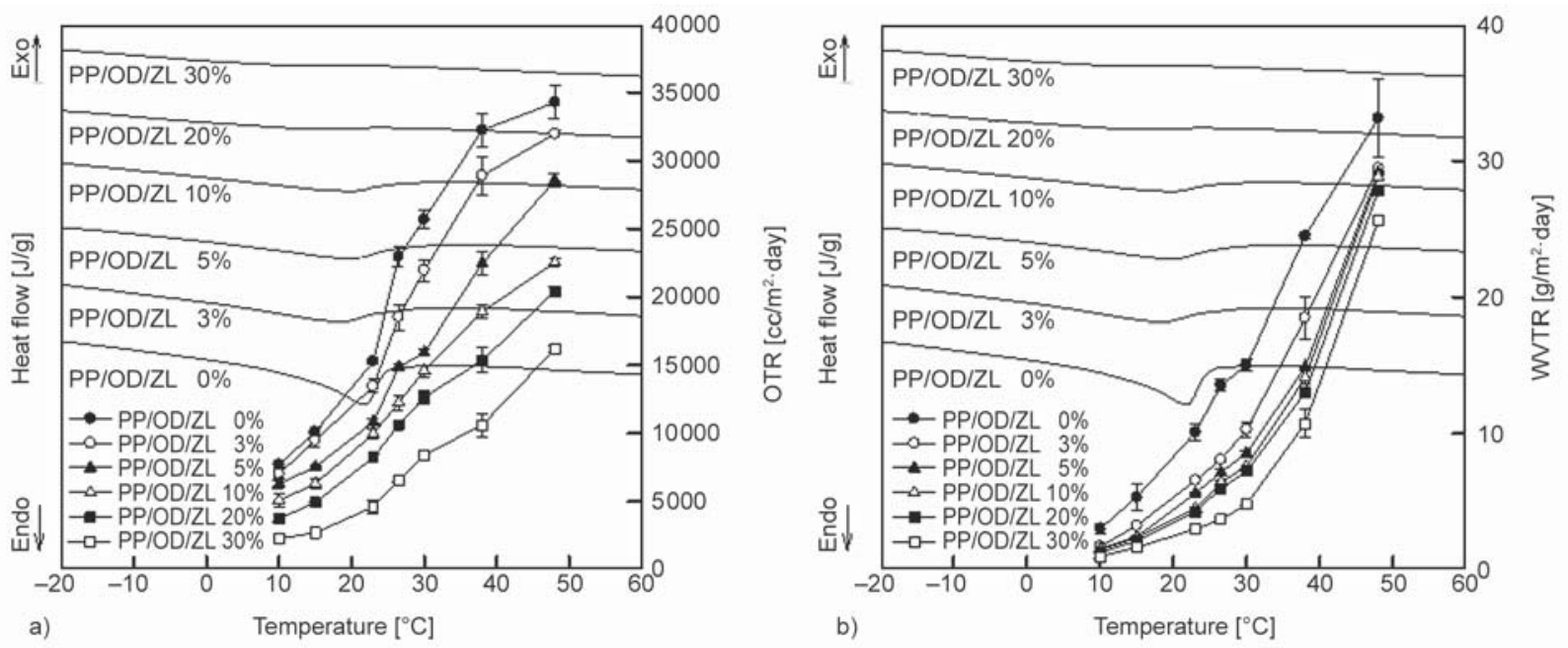

Figure 7. (a) OTR and (b) WVTR curves for the PP/OD/ZL composite films. 
Table 4. Comparison of oxygen (OP) and water vapor permeation (WVP) coefficient and activation energy of PP/OD/ZL composite films.

\begin{tabular}{|c|c|c|c|c|c|c|c|c|c|c|c|c|c|c|}
\hline \multirow{4}{*}{ Sample code } & \multicolumn{14}{|c|}{$\begin{array}{c}\text { Temperature range } \\
{\left[{ }^{\circ} \mathrm{C}\right]}\end{array}$} \\
\hline & \multicolumn{7}{|c|}{ OP } & \multicolumn{7}{|c|}{ WVP } \\
\hline & \multicolumn{3}{|c|}{$10 \sim 23{ }^{\circ} \mathrm{C}$} & \multicolumn{3}{|c|}{$30 \sim 48^{\circ} \mathrm{C}$} & \multirow{2}{*}{$\begin{array}{c}E_{\mathrm{op}_{+26.5}} \\
E_{\mathrm{op}_{-26.5}}\end{array}$} & \multicolumn{3}{|c|}{$10 \sim 23^{\circ} \mathrm{C}$} & \multicolumn{3}{|c|}{$30 \sim 48^{\circ} \mathrm{C}$} & \multirow{2}{*}{$\begin{array}{l}E_{\mathrm{wv}_{2}+26.5} \\
E_{\mathrm{wv}-26.5}\end{array}$} \\
\hline & $P_{\mathrm{op}_{-26.5}}$ & $E_{\text {op-26.5 }}$ & $R^{2}$ & $P_{\mathrm{op}+26.5}$ & $E_{0 p_{+26.5}}$ & $R^{2}$ & & $P_{\text {wvp }-26.5}$ & $E_{\text {wvp }-26.5}$ & $R^{2}$ & $P_{\mathrm{wvp}+26.5}$ & $E_{\mathrm{wvp}+26.5}$ & $R^{2}$ & \\
\hline $\mathrm{PP} / \mathrm{OD} / \mathrm{ZL} 0 \%$ & -18.0 & 36,615 & 1.00 & -27.3 & 12,673 & 0.87 & 0.34 & -18.7 & 63,527 & 0.99 & -30.2 & 35,126 & 0.97 & 0.55 \\
\hline $\mathrm{PP} / \mathrm{OD} / \mathrm{ZL} 3 \%$ & -19.0 & 34.553 & 0.99 & -25.9 & 16.769 & 0.91 & 0.49 & -16.4 & 70.427 & 0.99 & -26.0 & 46.782 & 0.99 & 0.66 \\
\hline $\mathrm{PP} / \mathrm{OD} / \mathrm{ZL} 5 \%$ & -20.9 & 30.446 & 0.99 & -22.5 & 25.947 & 0.96 & 0.85 & -17.4 & 68.357 & 0.99 & -23.0 & 54.930 & 0.99 & 0.80 \\
\hline $\mathrm{PP} / \mathrm{OD} / \mathrm{ZL} 10 \%$ & -18.4 & 36.690 & 0.99 & -25.6 & 18.531 & 0.98 & 0.58 & -21.3 & 59.270 & 0.99 & -21.2 & 59.669 & 0.99 & 1.00 \\
\hline $\mathrm{PP} / \mathrm{OD} / \mathrm{ZL} 20 \%$ & -16.2 & 42.618 & 0.99 & -24.6 & 21.360 & 0.99 & 0.50 & -19.3 & 64.267 & 0.99 & -21.0 & 60.426 & 0.99 & 0.94 \\
\hline $\mathrm{PP} / \mathrm{OD} / \mathrm{ZL} 30 \%$ & -18.5 & 38.394 & 0.98 & -22.1 & 28.783 & 0.98 & 0.75 & -22.1 & 58.339 & 0.99 & -15.7 & 74.734 & 0.99 & 1.28 \\
\hline
\end{tabular}

of OD portion in PP matrix. As the melting point of OD in PP matrix is traversed, the intensity of changes in activation energies for $\mathrm{O}_{2}$ and water vapor permeation of $\mathrm{PP} / \mathrm{OD} / \mathrm{ZL} 0 \%$ composite film was significantly decreased depending on the temperature (Table 4). As increase of ZL content in PP matrix, it is apparently showed that the magnitude of decrease in activation energy for $\mathrm{O}_{2}$ and water vapor permeation is relatively weak depending on the temperature change (Table 4). This is due to be hindered temperature-dependent morphological changes of OD resulting from the incorporation of ZL in PP matrix. That is, the incorporation of ZL prevents various penetrants such oxygen and water molecules from being absorbed and diffused into the PP/OD matrix. From these results, the observed decrease in the temperature-dependence of the oxygen and water vapor permeation jumps for the PP/OD/ZL composite films may be due to the change in their chemical and morphological structures originating from the ZL addition.

To further study effect on morphological changes against the oxygen and water vapor permeability, we have used a modified two-phase model proposed by Michaels and Bixler [28], and others [3, 5, 8] which takes into account both crystalline and amorphous structures as described by Equation (7):

$$
P_{\mathrm{c}}=P_{\mathrm{a}} \cdot \frac{1-\Phi}{\tau \beta}
$$

where $P_{\mathrm{c}}$ is the permeability of the composite film with both the amorphous and crystalline structures, $P_{\mathrm{a}}$ represents the permeability of the amorphous structure in the composite films, $\Phi$ is the volume fraction of the PP and ZL crystalline structures, $\tau$ is the tortuosity factor originating from the presence of PP and
$\mathrm{ZL}$, and $\beta$ is the factor related to the immobilization of amorphous structure owing to the PP and ZL crystalline structures. As shown in Figure 6, OD exhibits a phase-switchable morphological structure in the composite films in the temperature range between 10 and $30^{\circ} \mathrm{C}$. When the temperature increased from 10 to $30^{\circ} \mathrm{C}$, the crystalline structure of OD started to change into the amorphous one, leading to an increase in the chain mobility of OD in the PP matrix. As a result, the OD species in the composite films acted as temperature-dependent permeation channels for oxygen and water vapor molecules. However, the permeation jump was reduced with an increase in the $\mathrm{ZL}$ content because both the PP crystalline and porous nonpolar ZL phases might inhibit the temperaturedependent morphological conversion from the OD crystalline structure to the amorphous one.

The increase in the volume fraction of the ZL crystalline phase enhanced the related OD/ZL and PP/ZL interfacial interactions, which constantly maintained the immobilization of the OD species in the composite films during the OD phase change with increasing temperature. Note that the PP and ZL crystalline regions in the films are considered impermeable to oxygen and water vapors due to the formation of tortuous channels that prevent penetrants from sorption and diffusion into the composite films [19, 20]. As a result, the permeation jumps for oxygen and water vapors decreases.

\subsection{Contact angle and surface properties}

To investigate further variations in the surface properties of the PP/OD/ZL composite films due to variable ZL contents, their contact angles and surface energies were measured at $23^{\circ} \mathrm{C}$. As shown in Table 5, 
Table 5. Contact angles, surface energies, cohesive energy densities, and solubility parameters for the PP/OD/ZL composite films.

\begin{tabular}{|c|c|c|c|c|c|c|c|}
\hline \multirow[t]{2}{*}{ Sample code } & \multicolumn{2}{|c|}{$\begin{array}{c}\text { Contact angle } \\
{\left[{ }^{\circ}\right]}\end{array}$} & \multicolumn{3}{|c|}{$\begin{array}{c}\text { Surface energy, } \gamma^{\mathrm{s}} \\
{\left[\mathrm{mJ} / \mathrm{m}^{2}\right]}\end{array}$} & \multirow{2}{*}{$\begin{array}{c}e_{\mathrm{coh}} \cdot \mathbf{1 0}^{6} \\
{\left[\mathrm{~J} / \mathrm{m}^{3}\right]}\end{array}$} & \multirow{2}{*}{$\begin{array}{c}\delta \cdot 10^{3} \\
{\left[J^{1 / 2} / \mathrm{m}^{3 / 2}\right]}\end{array}$} \\
\hline & Water & Diiodomethane & Total & Dispersive & Polar & & \\
\hline $\mathrm{PP} / \mathrm{OD} / \mathrm{ZL} 0 \%$ & 84.1 & 35.6 & 42.2 & 40.2 & 2.0 & 422.1 & 20.5 \\
\hline $\mathrm{PP} / \mathrm{OD} / \mathrm{ZL} 3 \%$ & 87.4 & 41.5 & 39.1 & 37.5 & 1.6 & 376.4 & 19.4 \\
\hline $\mathrm{PP} / \mathrm{OD} / \mathrm{ZL} 5 \%$ & 88.6 & 43.2 & 38.1 & 36.7 & 1.4 & 362.1 & 19.0 \\
\hline $\mathrm{PP} / \mathrm{OD} / \mathrm{ZL} 10 \%$ & 89.4 & 43.9 & 37.7 & 36.4 & 1.3 & 356.4 & 18.9 \\
\hline $\mathrm{PP} / \mathrm{OD} / \mathrm{ZL} 20 \%$ & 92.6 & 45.7 & 36.5 & 35.7 & 0.8 & 339.5 & 18.4 \\
\hline $\mathrm{PP} / \mathrm{OD} / \mathrm{ZL} 30 \%$ & 94.6 & 48.1 & 35.1 & 34.5 & 0.6 & 320.2 & 17.9 \\
\hline
\end{tabular}

the PP/OD/ZL $0 \%$ composite film without ZL content was characterized by a water contact angle of $84.1^{\circ}$ and diiodomethane contact angle of $35.6^{\circ}$. This results are different from result of water contact angle $\left(101.2^{\circ}\right)$ and diidomethane contact angle of $\mathrm{PP} / \mathrm{OD} 20 \%\left(43.4^{\circ}\right)$ composite films, as described in our previous study [8]. By adding the Fusabond ${ }^{\circledR}$ E588 with amphiphilic properties, affinity against both water molecules and lipid materials of PP/OD/ZL $0 \%$ composite films were slightly increased. In terms of the chemical structure of composite films, water vapor permeability of composite films strongly has been changed as an increase of hydrophilicity $[8,44]$. This coincides with the water vapor permeability results of PP/OD/ZL composite films, as shown in Figure 7. Increasing the ZL content in the $\mathrm{PP} / \mathrm{OD} / \mathrm{ZL}$ composite films increased the corresponding water contact angles from 84.1 to $94.6^{\circ}$ and diiodomethane contact angles from 35.6 to $48.1^{\circ}$. The obtained results indicate that the hydrophobicity of the PP/OD/ZL composite films increased only slightly, while the potential interaction of the nonpolar liquid with the PP/ OD/ZL composite films decreased with an increase in the ZL content.

The total surface free energy contains polar and dispersive surface components, which are equal to 2.0 and $40.2 \mathrm{~mJ} / \mathrm{m}^{2}$ for the PP/OD composite film with $0 \%$ ZL. However, increasing ZL content decreases the polar energy of the PP/OD/ZL composite films from 2.0 to $0.6 \mathrm{~mJ} / \mathrm{m}^{2}$ and the corresponding dispersive energy from 40.2 to $34.5 \mathrm{~mJ} / \mathrm{m}^{2}$. Overall, increasing ZL content decreases the total surface free energy from 42.2 to $35.1 \mathrm{~mJ} / \mathrm{m}^{2}$. The observed trends for the composite surface energy are similar to those obtained for the solubility parameter, which was equal to $20.5 \cdot 10^{3} \mathrm{~J}^{1 / 2} / \mathrm{m}^{3 / 2}$ for PP/OD with $0 \% \mathrm{ZL}$ and slightly decreased to $17.9 \cdot 10^{3} \mathrm{~J}^{1 / 2} / \mathrm{m}^{3 / 2}$ for the $\mathrm{PP} / \mathrm{OD} / \mathrm{ZL}$ composite films, while the solubility parameter of water was $47.9 \cdot 10^{3} \mathrm{~J}^{1 / 2} / \mathrm{m}^{3 / 2}[2,8,23]$. Thus, the difference between the solubility parameters for the composite films and water vapors was slightly increased by adding hydrophobic and non-polar ZL species, indicating that it was difficult for water vapors to penetrate into the $\mathrm{PP} / \mathrm{OD} / \mathrm{ZL}$ composite films.

\subsection{Mechanical properties}

The mechanical properties of pure PP and three different $\mathrm{PP} / \mathrm{OD} / \mathrm{ZL}$ composite films were investigated using the universal testing machine, and the obtained results are summarized in Figure 8 and Table 6 [13, $45,46]$. The tensile strength and elongation at break of pure PP are $39.0 \mathrm{MPa}$ and $255.4 \%$, respectively. The tensile strength and elongation at break of the $\mathrm{PP} / \mathrm{OD}$ composite film without ZL are lowered to 23.1 MPa and 219.6\%, respectively. This might be due to the low interfacial interaction between PP and OD and poor dispersion and agglomeration originating from OD-OD interaction. In addition, the OD addition might prevent the formation of a PP continuous phase, causing the initiation and propagation of stress cracking during the film deformation [13].

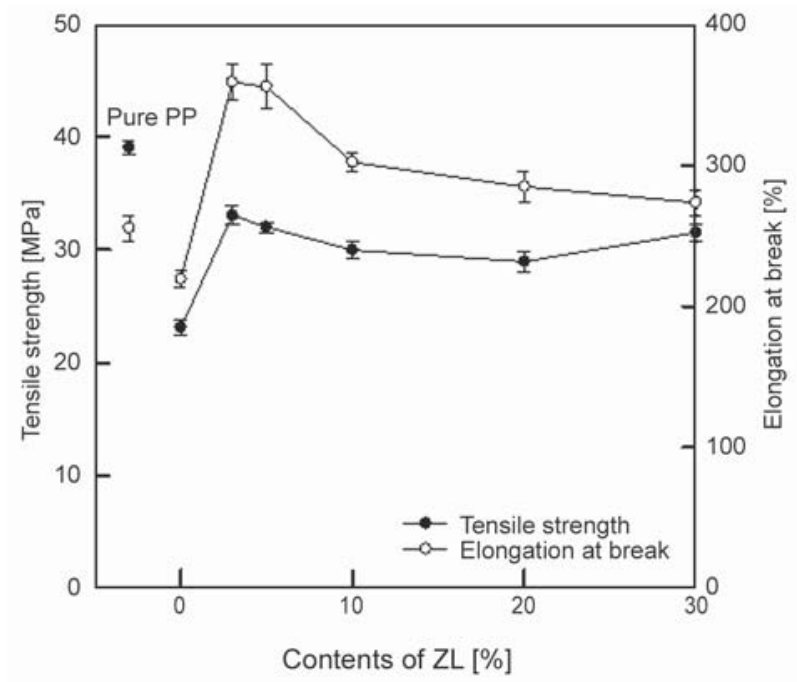

Figure 8. Tensile strength and elongation at break of the $\mathrm{PP} / \mathrm{OD} / \mathrm{ZL}$ composite films. 
Table 6. Tensile strength and elongation at break results for the PP/OD/ZL composite films after the contact with the food simulants and thermal treatment.

\begin{tabular}{|c|c|c|c|c|c|c|}
\hline \multicolumn{7}{|c|}{$\begin{array}{l}\text { Tensile strength } \\
\text { [MPa] }\end{array}$} \\
\hline Sample code & Standard & $\begin{array}{c}\text { DI water } \\
\left(10 \text { days at } 40^{\circ} \mathrm{C}\right)\end{array}$ & $\begin{array}{c}3 \% \text { acetic acid } \\
\left(10 \text { days at } 40^{\circ} \mathrm{C}\right)\end{array}$ & $\begin{array}{c}10 \% \text { ethanol } \\
\left(10 \text { days at } 40^{\circ} \mathrm{C}\right)\end{array}$ & $\begin{array}{c}\text { isooctane } \\
\left(10 \text { days at } 40^{\circ} \mathrm{C}\right)\end{array}$ & $\begin{array}{l}50^{\circ} \mathrm{C}(2 \text { days }) \rightarrow \\
5^{\circ} \mathrm{C}(2 \text { days })\end{array}$ \\
\hline PP/OD/ZL 0\% & $23.1 \pm 0.6$ & $\begin{array}{l}23.2 \pm 0.6 \\
(100.4)\end{array}$ & $\begin{array}{r}22.6 \pm 1.1 \\
(97.9)^{\mathrm{a}}\end{array}$ & $\begin{array}{c}22.9 \pm 1.8 \\
(99.3)^{\mathrm{a}}\end{array}$ & $\begin{array}{c}21.8 \pm 0.9 \\
(94.3)^{\mathrm{a}}\end{array}$ & $\begin{array}{l}23.6 \pm 2.0 \\
(101.9)\end{array}$ \\
\hline PP/OD/ZL 3\% & $33.1 \pm 0.8$ & $\begin{array}{r}31.1 \pm 1.1 \\
(94.1)^{\mathrm{a}} \\
\end{array}$ & $\begin{array}{l}33.2 \pm 1.0 \\
(100.3)^{\mathrm{a}}\end{array}$ & $\begin{array}{c}32.4 \pm 2.0 \\
(98.0)^{\mathrm{a}}\end{array}$ & $\begin{array}{c}25.9 \pm 1.0 \\
(78.5)^{\mathrm{a}}\end{array}$ & $\begin{array}{r}30.7 \pm 1.5 \\
(93.0)^{\mathrm{a}}\end{array}$ \\
\hline PP/OD/ZL 5\% & $32.0 \pm 0.4$ & $\begin{array}{r}29.2 \pm 1.0 \\
(91.2)^{\mathrm{a}} \\
\end{array}$ & $\begin{array}{r}29.4 \pm 2.0 \\
(91.8)^{\mathrm{a}}\end{array}$ & $\begin{array}{c}30.1 \pm 2.2 \\
(94.1)^{\mathrm{a}}\end{array}$ & $\begin{array}{c}25.0 \pm 0.6 \\
(78.6)^{\mathrm{a}}\end{array}$ & $\begin{array}{c}30 \pm 1.6 \\
(96.6)^{\mathrm{a}}\end{array}$ \\
\hline $\mathrm{PP} / \mathrm{OD} / \mathrm{ZL} 10 \%$ & $29.9 \pm 0.7$ & $\begin{array}{r}27.4 \pm 2.0 \\
(91.4)^{\mathrm{a}}\end{array}$ & $\begin{array}{r}26.4 \pm 0.4 \\
(88.0)^{\mathrm{a}}\end{array}$ & $\begin{array}{l}28.7 \pm 0.7 \\
(95.8)^{\mathrm{a}}\end{array}$ & $\begin{array}{c}26.3 \pm 0.9 \\
(87.7)^{\mathrm{a}}\end{array}$ & $\begin{array}{r}29.2 \pm 1.6 \\
(97.3)^{\mathrm{a}}\end{array}$ \\
\hline $\mathrm{PP} / \mathrm{OD} / \mathrm{ZL} 20 \%$ & $29.0 \pm 0.9$ & $\begin{array}{r}27.2 \pm 1.3 \\
(93.9)^{\mathrm{a}} \\
\end{array}$ & $\begin{array}{r}27.6 \pm 1.4 \\
(95.4)^{\mathrm{a}} \\
\end{array}$ & $\begin{array}{l}28.0 \pm 1.1 \\
(96.7)^{\mathrm{a}}\end{array}$ & $\begin{array}{c}27.6 \pm 1.3 \\
(95.3)^{\mathrm{a}}\end{array}$ & $\begin{array}{r}28.9 \pm 1.8 \\
(99.7)^{\mathrm{a}}\end{array}$ \\
\hline $\mathrm{PP} / \mathrm{OD} / \mathrm{ZL} 30 \%$ & $31.5 \pm 0.8$ & $\begin{array}{r}27.9 \pm 1.7 \\
(88.5)^{\mathrm{a}}\end{array}$ & $\begin{array}{r}30.7 \pm 1.6 \\
(97.2)^{\mathrm{a}}\end{array}$ & $\begin{array}{c}27.9 \pm 2.6 \\
(88.6)^{\mathrm{a}}\end{array}$ & $\begin{array}{c}27.4 \pm 1.5 \\
(86.8)^{\mathrm{a}}\end{array}$ & $\begin{array}{r}29.7 \pm 2.0 \\
(94.8)^{\mathrm{a}}\end{array}$ \\
\hline \multicolumn{7}{|c|}{$\begin{array}{c}\text { Elongation at break } \\
{[\%]}\end{array}$} \\
\hline Sample code & Standard & $\begin{array}{c}\text { DI water } \\
\left(10 \text { days at } 40^{\circ} \mathrm{C}\right)\end{array}$ & $\begin{array}{l}3 \% \text { acetic acid } \\
\left(10 \text { days at } 40^{\circ} \mathrm{C}\right)\end{array}$ & $\begin{array}{c}10 \% \text { ethanol } \\
\left(10 \text { days at } 40^{\circ} \mathrm{C}\right)\end{array}$ & $\begin{array}{c}\text { isooctane } \\
\left(10 \text { days at } 40^{\circ} \mathrm{C}\right)\end{array}$ & $\begin{array}{l}50^{\circ} \mathrm{C}(2 \text { days }) \rightarrow \\
5^{\circ} \mathrm{C}(2 \text { days })\end{array}$ \\
\hline PP/OD/ZL 0\% & $219.6 \pm 6.1$ & $\begin{array}{l}217.5 \pm 13.0 \\
(99.1)^{\mathrm{b}}\end{array}$ & $\begin{array}{c}206.5 \pm 12.8 \\
(94.0)^{\mathrm{b}}\end{array}$ & $\begin{array}{c}212.4 \pm 5.1 \\
(96.7)^{\mathrm{b}}\end{array}$ & $\begin{array}{r}6.0 \pm 0.4 \\
(2.7)^{\mathrm{b}}\end{array}$ & $\begin{array}{l}224.7 \pm 7.7 \\
(102.3)^{\mathrm{b}}\end{array}$ \\
\hline PP/OD/ZL 3\% & $358.8 \pm 12.2$ & $\begin{array}{c}338.5 \pm 14.5 \\
(94.3)^{\mathrm{b}}\end{array}$ & $\begin{array}{c}335.0 \pm 6.8 \\
(93.4)^{\mathrm{b}}\end{array}$ & $\begin{array}{c}335.6 \pm 14.7 \\
(93.5)^{\mathrm{b}}\end{array}$ & $\begin{array}{c}255.7 \pm 10.0 \\
(71.3)^{\mathrm{b}}\end{array}$ & $\begin{array}{c}323.2 \pm 13.9 \\
(90.1)^{\mathrm{b}}\end{array}$ \\
\hline PP/OD/ZL 5\% & $355.5 \pm 15.8$ & $\begin{array}{c}300.0 \pm 10.5 \\
(84.4)^{\mathrm{b}}\end{array}$ & $\begin{array}{l}309.3 \pm 21.8 \\
(87.0)^{\mathrm{b}}\end{array}$ & $\begin{array}{l}345.3 \pm 13.4 \\
(97.1)^{\mathrm{b}}\end{array}$ & $\begin{array}{c}335.0 \pm 12.1 \\
(66.1)^{\mathrm{b}}\end{array}$ & $\begin{array}{c}338.0 \pm 16.2 \\
\quad(95.1)^{\mathrm{b}}\end{array}$ \\
\hline $\mathrm{PP} / \mathrm{OD} / \mathrm{ZL} 10 \%$ & $302.1 \pm 7.2$ & $\begin{array}{l}280.4 \pm 10.9 \\
(92.8)^{\mathrm{b}}\end{array}$ & $\begin{array}{l}261.9 \pm 17.7 \\
(86.7)^{\mathrm{b}}\end{array}$ & $\begin{array}{l}274.9 \pm 8.5 \\
(91.0)^{\mathrm{b}}\end{array}$ & $\begin{array}{c}257.4 \pm 13.4 \\
(85.2)^{\mathrm{b}}\end{array}$ & $\begin{array}{c}303.9 \pm 8.4 \\
(100.6)^{\mathrm{b}}\end{array}$ \\
\hline $\mathrm{PP} / \mathrm{OD} / \mathrm{ZL} 20 \%$ & $284.7 \pm 10.8$ & $\begin{array}{c}264.0 \pm 11.5 \\
(92.7)^{\mathrm{b}}\end{array}$ & $\begin{array}{c}281.0 \pm 11.7 \\
(98.7)^{\mathrm{b}}\end{array}$ & $\begin{array}{c}251.4 \pm 13.9 \\
(88.3)^{\mathrm{b}}\end{array}$ & $\begin{array}{c}279.2 \pm 9.1 \\
(98.0)^{\mathrm{b}}\end{array}$ & $\begin{array}{c}294.5 \pm 14.7 \\
(103.4)^{\mathrm{b}}\end{array}$ \\
\hline $\mathrm{PP} / \mathrm{OD} / \mathrm{ZL} 30 \%$ & $273.5 \pm 9.1$ & $\begin{array}{c}236.7 \pm 9.3 \\
(86.5)^{\mathrm{b}}\end{array}$ & $\begin{array}{c}250.9 \pm 7.9 \\
(91.7)^{\mathrm{b}}\end{array}$ & $\begin{array}{c}264.6 \pm 15.5 \\
(96.8)^{\mathrm{b}}\end{array}$ & $\begin{array}{c}252.6 \pm 10.7 \\
(92.3)^{\mathrm{b}}\end{array}$ & $\begin{array}{c}261.3 \pm 10.8 \\
(95.5)^{\mathrm{b}}\end{array}$ \\
\hline
\end{tabular}

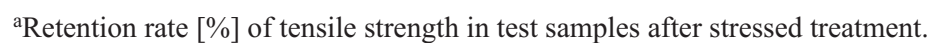

${ }^{b}$ Retention rate [\%] of elongation at break in test samples after stressed treatment.

However, compared to the PP/OD composite film without ZL, the PP/OD/ZL composite films exhibited enhanced tensile strength and elongation at break owing to the ZL non-polar porous structure. The probable reason for this is that ZL with its hydrophobic and non-polar structure physically interacted well with relatively low molecular weight $\mathrm{OD}$, which decreased the flow rate of OD in the composite films during the extrusion process. Furthermore, the porous ZL species might immobilize the OD and PP chains at the PP/OD interface. This can aid in maintaining a constant thickness of the composite films and uniform dispersion of the OD molecules in the PP matrix by modulating the flowability of the two components of different molecular weights. As a result, the tensile strength and elongation at break of the composite films are enhanced.

\subsection{Physical properties of the composite films exposed to food simulants and thermal treatment}

In order to protect packaging applications from contamination, it is critical to evaluate physical properties of a packaging material after the contact with various products, high pressure, or thermal treatment $[15,16]$. In this study, we have investigated the OTRs and mechanical properties of the composite films exposed to four different food simulants and thermal treatment. The effects of the food simulants and thermal treatment on the mechanical properties of the $\mathrm{PP} / \mathrm{OD} / \mathrm{ZL}$ composite films are presented in Table 6. The stress treatment performed using deionized water, acetic acid, and ethanol as well as heat treatment produced slight deteriorations of mechanical properties of the composite films with variations not exceeding 
Table 7. OTR data obtained for the PP/OD/ZL composite films after the contact with food simulants.

\begin{tabular}{|c|c|c|c|c|c|}
\hline \multirow{2}{*}{ Sample code } & \multicolumn{5}{|c|}{$\begin{array}{c}\text { OTR } \\
{\left[\mathrm{cc} / \mathrm{m}^{2} \cdot \text { day at } 23^{\circ} \mathrm{C}\right]}\end{array}$} \\
\hline & Standard & $\begin{array}{c}\text { DI water } \\
\left(10 \text { days at } 40^{\circ} \mathrm{C}\right)\end{array}$ & $\begin{array}{c}3 \% \text { acetic acid } \\
\left(10 \text { days at } 40^{\circ} \mathrm{C}\right)\end{array}$ & $\begin{array}{c}10 \% \text { ethanol } \\
\left(10 \text { days at } 40^{\circ} \mathrm{C}\right)\end{array}$ & $\begin{array}{c}\text { isooctane } \\
\left(10 \text { days at } 40^{\circ} \mathrm{C}\right)\end{array}$ \\
\hline PP/OD/ZL 0\% & $15301 \pm 161$ & $\begin{array}{c}67724 \pm 2895 \\
(442.6)^{*}\end{array}$ & $\begin{array}{c}43782 \pm 3422 \\
(286.1)^{*}\end{array}$ & $\begin{array}{c}62909 \pm 2287 \\
(411.1)^{*}\end{array}$ & $\begin{array}{c}33337 \pm 900 \\
(217.9)^{*}\end{array}$ \\
\hline PP/OD/ZL 3\% & $13486 \pm 472$ & $\begin{array}{c}12577 \pm 1680 \\
(93.3)^{*}\end{array}$ & $\begin{array}{c}12852 \pm 896 \\
(95.3)^{*}\end{array}$ & $\begin{array}{c}12058 \pm 1376 \\
(89.4)^{*}\end{array}$ & $\begin{array}{r}1857 \pm 91 \\
(13.8)^{*}\end{array}$ \\
\hline $\mathrm{PP} / \mathrm{OD} / \mathrm{ZL} 5 \%$ & $10871 \pm 259$ & $\begin{array}{c}10658 \pm 1006 \\
(98.0)^{*}\end{array}$ & $\begin{array}{c}10310 \pm 146 \\
(94.8)^{*}\end{array}$ & $\begin{array}{c}10446 \pm 310 \\
(96.1)^{*}\end{array}$ & $\begin{array}{r}1827 \pm 96 \\
(16.8)^{*}\end{array}$ \\
\hline PP/OD/ZL 10\% & $9999 \pm 379$ & $\begin{array}{l}9291 \pm 616 \\
(92.9)^{*}\end{array}$ & $\begin{array}{c}9324 \pm 1278 \\
(93.2)^{*}\end{array}$ & $\begin{array}{c}9084 \pm 369 \\
(90.8)^{*}\end{array}$ & $\begin{array}{r}1813 \pm 89 \\
(18.1)^{*}\end{array}$ \\
\hline $\mathrm{PP} / \mathrm{OD} / \mathrm{ZL} 20 \%$ & $8255 \pm 334$ & $\begin{array}{c}6426 \pm 800 \\
(77.8)^{*}\end{array}$ & $\begin{array}{c}6942 \pm 741 \\
(84.1)^{*}\end{array}$ & $\begin{array}{c}6680 \pm 143 \\
(80.9)^{*}\end{array}$ & $\begin{array}{c}1845 \pm 111 \\
(22.4)^{*}\end{array}$ \\
\hline PP/OD/ZL 30\% & $4627 \pm 448$ & $\begin{array}{c}4897 \pm 84 \\
(105.8)^{*}\end{array}$ & $\begin{array}{r}4200 \pm 22 \\
(90.8)^{*}\end{array}$ & $\begin{array}{r}4883 \pm 50 \\
(105.5)^{*}\end{array}$ & $\begin{array}{r}1631 \pm 72 \\
(35.2)^{*}\end{array}$ \\
\hline
\end{tabular}

${ }^{*}$ Retention rate (\%) of OTR in test samples after stressed treatment.

$15 \%$. When the PP/OD composite film was exposed to iso-octane, a $97 \%$ decrease in elongation at break was observed, which could be attributed to the fact the non-polar chemical structure of iso-octane (which was similar to that of OD) could easily adhere and penetrate into the OD phase or the interface between the OD and PP species, resulting in disruption and decrease in flexibility of the composite morphological structure. However, the elongation at break for the $\mathrm{PP} / \mathrm{OD} / \mathrm{ZL}$ composite films increased with an increase in the ZL content. As indicated by the obtained WAXD, density, and mechanical property data, the incorporation of ZL into the structures of the PP/OD composite films produced enhanced interfacial interactions between PP and OD, which were possibly able to resist contaminations caused by the presence of lipid simulants.

The changes in the OTR values for the PP/OD/ZL composite films produced by the contact with the food simulants is listed in Table 7. In particular, the OTR value for the $\mathrm{PP} / \mathrm{OD}$ composite film with $0 \% \mathrm{ZL}$ was significantly increased after the contact with food simulants since the accompanying morphological changes weaken the interfacial interactions between $\mathrm{PP}$ and $\mathrm{OD}$, making it easier for $\mathrm{O}_{2}$ molecules to penetrate through the composite film surface. However, it can be expected that the addition of ZL into the $\mathrm{PP} / \mathrm{OD}$ composite film may induce a relatively dense structure containing both the PP and OD species, which would make it difficult for the simulant molecules to dissolve and penetrate into the composite films. As expected, the variations of the OTR values for the PP/OD/ZL composite films did not exceed $25 \%$. However, the observed decrease in the OTR values for the $\mathrm{PP} / \mathrm{OD} / \mathrm{ZL}$ composite films was more prominent in the case of the iso-octane treatment, corresponding to $13.8 \%$ for the PP/OD/ZL composite film with $3 \% \mathrm{ZL}$. The OD phase of the composite

Table 8. OTR data obtained for the PP/OD/ZL composite films after thermal treatment.

\begin{tabular}{|c|c|c|c|c|}
\hline \multirow[t]{2}{*}{ Sample code } & \multicolumn{4}{|c|}{$\begin{array}{c}\text { OTR } \\
{\left[\mathrm{cc} / \mathrm{m}^{2} \cdot \text { day at } 23^{\circ} \mathrm{C}\right]}\end{array}$} \\
\hline & Standard & $1^{\text {st }}$ cycle & $2^{\text {nd }}$ cycle & $3^{\text {rd }}$ cycle \\
\hline PP/OD/ZL 0\% & $15301 \pm 161$ & $\begin{array}{r}14928 \pm 463 \\
(97.6)^{*}\end{array}$ & $\begin{array}{c}15208 \pm 676 \\
(99.4)^{*}\end{array}$ & $\begin{array}{c}14848 \pm 469 \\
(97.0)^{*}\end{array}$ \\
\hline PP/OD/ZL 3\% & $13486 \pm 472$ & $\begin{array}{l}13737 \pm 8 \\
(101.9)^{*}\end{array}$ & $\begin{array}{r}14030 \pm 681 \\
(104.0)^{*}\end{array}$ & $\begin{array}{c}13156 \pm 1028 \\
(97.6)^{*}\end{array}$ \\
\hline PP/OD/ZL 5\% & $10871 \pm 259$ & $\begin{array}{r}10497 \pm 306 \\
(96.6)^{*}\end{array}$ & $\begin{array}{r}11065 \pm 139 \\
(101.8)^{*}\end{array}$ & $\begin{array}{c}11371 \pm 169 \\
(104.6)^{*}\end{array}$ \\
\hline PP/OD/ZL $10 \%$ & $9999 \pm 379$ & $\begin{array}{c}9888 \pm 292 \\
(98.9)^{*}\end{array}$ & $\begin{array}{r}10572 \pm 432 \\
(105.7)^{*}\end{array}$ & $\begin{array}{c}10284 \pm 43 \\
(102.8)^{*}\end{array}$ \\
\hline PP/OD/ZL 20\% & $8255 \pm 334$ & $\begin{array}{c}7758 \pm 316 \\
(94.3)^{*}\end{array}$ & $\begin{array}{r}7915 \pm 158 \\
(96.2)^{*}\end{array}$ & $\begin{array}{c}7646 \pm 100 \\
(92.6)^{*}\end{array}$ \\
\hline PP/OD/ZL 30\% & $4627 \pm 448$ & $\begin{array}{c}4794 \pm 317 \\
(103.6)^{*}\end{array}$ & $\begin{array}{r}4313 \pm 373 \\
(93.2)^{*}\end{array}$ & $\begin{array}{r}4179 \pm 56 \\
(90.3)^{*}\end{array}$ \\
\hline
\end{tabular}

${ }^{*}$ Retention rate [\%] of OTR in test samples after thermal treatment. 
films strongly interacted with the iso-octane species, thus removing any obstacles for dissolving and diffusing $\mathrm{O}_{2}$ molecules into the composite films.

The changes in the OTR values for the PP/OD/ZL composite films were measured after thermal treatments at $50^{\circ} \mathrm{C}$ for 2 day and $5^{\circ} \mathrm{C}$ for 2 day. The experiments were conducted in three cycles. As shown in Table 8, the OTR results obtained after the heat treatment exhibited a trend, which was different from that observed for the OTR data measured after the contact with the food simulants. After the heat treatment, the variations of the OTR values for all the composite films did not exceed $10 \%$. From the practical viewpoint, the $\mathrm{PP} / \mathrm{OD} / \mathrm{ZL}$ composite films are relatively compatible with the heat treatment and thus can be possibly utilized in various fields that require temperature-dependent control of gas permeability properties such as agricultural products for $\mathrm{O}_{2} / \mathrm{CO}_{2}$ control, medical devices for sterilization, and microwavable products for vapor emission applications.

\section{Conclusions}

Six different PP/OD/ZL composite films for packaging applications with temperature-dependent permeability properties were prepared. The addition of ZL into PP/OD composite films changed their morphological and chemical structures and increased interfacial interactions between the OD and PP species. The OD phases in the PP/OD/ZL composite films acted as diffusion channels for the temperature-dependent $\mathrm{O}_{2}$ and water vapor permeation. However, the enhancement of the crystalline structure and interfacial interactions due to the ZL incorporation prevented the movement of the OD species in the composite films near the phase change temperature (between 10 and $30^{\circ} \mathrm{C}$ ). In addition, the new crystalline regions formed tortuous paths that prevented the sorption and diffusion of $\mathrm{O}_{2}$ and water vapor molecules into the composite films. As a result, permeation jumps for $\mathrm{O}_{2}$ and water vapors were reduced near the phase change temperature of OD. However, the incorporation of ZL species with porous and nonpolar structures into the PP/OD composites films allows the flowability control between the OD and PP phases originating from their different molecular weights, which improve the dispersion of OD in the PP matrix and interfacial interactions between the PP and OD species. Such an improvement significantly enhances thermal stability, mechanical properties, and OTRs of the composite films after the contact with food simulants and thermal treatment. As indicated by the obtained results, the PP/OD/ZL composite films can be used as packaging materials to preserve the quality of packaged products by controlling their temperature-dependent gas permeability properties.

\section{Acknowledgements}

This work was supported by the National Research Foundation of Korea (NRF) grant funded by the Korea government (2017R1A2B4011234 and NRF-2017R1A6A3A03012167).

\section{References}

[1] Fuciños C., Fuciños P., Míguez M., Katime I., Pastrana L. M., Rúa M. L.: Temperature- and pH-sensitive nanohydrogels of poly( $N$-isopropylacrylamide) for food packaging applications: Modelling the swelling-collapse behaviour. PLoS One, 9, 1-15 (2014).

https://doi.org/10.1371/journal.pone.0087190

[2] Kim D., Park I., Seo J., Han H., Jang W.: Effects of the paraffin wax (PW) content on the thermal and permeation properties of the LDPE/PW composite films. Journal of Polymer Research, 22, 19/1-19/11 (2015).

https://doi.org/10.1007/s10965-014-0650-x

[3] Kirkland B. S.: Gas transport properties of poly ( $n$-alkyl acrylate) blends and modeling of modified atmosphere storage using selective and non-selective membranes. $\mathrm{PhD}$ thesys, University of Texas at Austin (2007).

[4] Siracusa V.: Food packaging permeability behaviour: A report. International Journal of Polymer Science, 2012, 302029/1-302029/11 (2012). https://doi.org/10.1155/2012/302029

[5] O'Leary K. A., Paul D. R.: Physical properties of poly (n-alkyl acrylate) copolymers. Part 1 . Crystalline/crystalline combinations. Polymer, 47, 1226-1244 (2006). https://doi.org/10.1016/j.polymer.2005.12.005

[6] Wang Z. F., Wang B., Ding X. M., Zhang M., Liu L. M., Qi N., Hu J. L.: Effect of temperature and structure on the free volume and water vapor permeability in hydrophilic polyurethanes. Journal of Membrane Science, 241, 355-361 (2004). https://doi.org/10.1016/j.memsci.2004.04.037

[7] Jeong H. M., Ahn B. K., Cho S. M., Kim B. K.: Water vapor permeability of shape memory polyurethane with amorphous reversible phase. Journal of Polymer Science Part B: Polymer Physics, 38, 3009-3017 (2000). https://doi.org/10.1002/10990488(20001201)38:23<3009::AID-POLB30>3.0.CO;2-8

[8] Kim D., Lim M., Seo J.: Preparation of polypropylene/ octadecane composite films and their use in the packaging of cherry tomatoes. Journal of Applied Polymer Science, 133, 44087/1-44087/12 (2016).

https://doi.org/10.1002/app.44087 
[9] Kwon H., Kim D., Lee K-D., Lee, Seo J., Lee H-J.: The effect of coating process and additives on EVA coated Tyvek $^{\circledR}$ for gas sterilizable medical packaging applications. Packaging Technology and Science, 30, 195-208 (2017).

https://doi.org/10.1002/pts.2293

[10] Mhike W., Focke W. W., Mofokeng W. J. P., Luyt A. S.: Thermally conductive phase-change materials for energy storage based on low-density polyethylene, soft Fischer-Tropsch wax and graphite. Thermochimica Acta, 527, 75-82 (2012).

https://doi.org/10.1016/j.tca.2011.10.008

[11] Molefi J. A., Luyt A. S., Krupa I.: Investigation of thermally conducting phase-change materials based on polyethylene/wax blends filled with copper particles. Journal of Applied Polymer Science, 116, 1766-1774 (2010). https://doi.org/10.1002/app.31653

[12] Zhang Z., Shi G., Wang S., Fang X., Liu X.: Thermal energy storage cement mortar containing $n$-octadecane/ expanded graphite composite phase change material. Renewable Energy, 50, 670-675 (2013). https://doi.org/10.1016/j.renene.2012.08.024

[13] AlMaadeed M. A., Labidi S., Krupa I., Ouederni M.: Effect of waste wax and chain structure on the mechanical and physical properties of polyethylene. Arabian Journal of Chemistry, 8, 388-399 (2015). https://doi.org/10.1016/j.arabjc.2014.01.006

[14] Bao Z., Yu L., Dou T., Gong Y., Zhang Q., Ren Q., Lu X., Deng S.: Adsorption equilibria of $\mathrm{CO}_{2}, \mathrm{CH}_{4}, \mathrm{~N}_{2}, \mathrm{O}_{2}$, and Ar on high silica zeolites. Journal of Chemical and Engineering Data, 56, 4017-4023 (2011).

https://doi.org/10.1021/je200394p

[15] Galotto M. J., Ulloa P. A., Hernández D., FernándezMartín F., Gavara R., Guarda A.: Mechanical and thermal behaviour of flexible food packaging polymeric films materials under high pressure/temperature treatments. Packaging Technology and Science, 21, 297 308 (2008).

https://doi.org/10.1002/pts. 807

[16] Siracusa V., Lotti N., Munari A., Rosa D. M.: Poly(butylene succinate) and poly(butylene succinate-co-adipate) for food packaging applications: Gas barrier properties after stressed treatments. Polymer Degradation and Stability, 118, 35-45 (2015).

https://doi.org/10.1016/j.polymdegradstab.2015.04.026

[17] Regulation (EC) No 1935/2004 of the European parliament and of the council on materials and articles intended to come into contact with food and repealing Directives 80/590/EEC and 89/109/EEC (2004).

[18] Regulation (EU) No 10/2011 on plastic materials and articles intended to come into contact with food (2011).

[19] Kim D., Jang M., Seo J., Nam K-H., Han H., Khan S. B.: UV-cured poly(urethane acrylate) composite films containing surface-modified tetrapod $\mathrm{ZnO}$ whiskers. Composites Science and Technology, 75, 84-92 (2013). https://doi.org/10.1016/j.compscitech.2012.12.007
[20] Lee Y., Kim D., Seo J., Han H., Khan S. B.: Preparation and characterization of poly(propylene carbonate)/exfoliated graphite nanocomposite films with improved thermal stability, mechanical properties and barrier properties. Polymer International, 62, 1386-1394 (2013). https://doi.org/10.1002/pi.4434

[21] Cai Q., Xu R., Chen X., Chen C., Mo H., Lei C.: Structure and properties of melt-stretching polypropylene/silicon dioxide compound microporous membrane. Polymer Composites, 37, 2684-2691 (2016).

https://doi.org/10.1002/pc.23462

[22] Shimizu R. N., Demarquette N. R.: Evaluation of surface energy of solid polymers using different models. Journal of Applied Polymer Science, 76, 1831-1845 (2000). https://doi.org/10.1002/(SICI)10974628(20000620)76:12<1831::AID-APP14>3.0.CO;2-Q

[23] Khayet M., Chowdhury G., Matsuura T.: Surface modification of polyvinylidene fluoride pervaporation membranes. AIChE Journal, 48, 2833-2843 (2002). https://doi.org/10.1002/aic.690481211

[24] Khayet M., Fernández V.: Estimation of the solubility parameters of model plant surfaces and agrochemicals: A valuable tool for understanding plant surface interactions. Theoretical Biology and Medical Modelling, 9, 45/1-45/21 (2012). https://doi.org/10.1186/1742-4682-9-45

[25] Jansen J. C., van der Gaan F. J., van Bekkum H.: Identification of ZSM-Type and other 5-ring containing zeolites by I.R. spectroscopy. Zeolites, 4, 369-372 (1984). https://doi.org/10.1016/0144-2449(84)90013-7

[26] Sari Z. G. L. V., Younesi H., Kazemian H.: Synthesis of nanosized ZSM-5 zeolite using extracted silica from rice husk without adding any alumina source. Applied Nanoscience, 5, 737-745 (2015). https://doi.org/10.1007/s13204-014-0370-x

[27] Del Castillo-Castro T., Castillo-Ortega M. M., HerreraFranco P. J., Rodríguez-Félix D. E.: Compatibilization of polyethylene/polyaniline blends with polyethylenegraft-maleic anhydride. Journal of Applied Polymer Science, 119, 2895-2901 (2011).

https://doi.org/10.1002/app.32971

[28] Michaels A., Bixler H. J.: Flow of gases through polyethylene. Journal of Polymer Science Part A: Polymer Chemistry, 50, 413-439 (1961). https://doi.org/10.1002/pol.1961.1205015412

[29] Urbaniak-Domagala W.: The use of the spectrometric technique FTIR-ATR to examine the polymers surface. in 'Advanced aspects of spectroscopy' (ed.: Farrukh M. A.) InTech, Rijeka, 85-104 (2012). https://doi.org/10.5772/48143

[30] Sevegney M. S., Kannan R. M., Siedle A. R., Percha P. A.: FTIR spectroscopic investigation of thermal effects in semi-syndiotactic polypropylene. Journal of Polymer Science Part B: Polymer Physics, 43, 439-461 (2005). https://doi.org/10.1002/polb.20334 
[31] Ramaraj B.: Crosslinked poly(vinyl alcohol) and starch composite films. II. Physicomechanical, thermal properties and swelling studies. Journal of Polymer Science, 103, 909-916 (2007).

https://doi.org/10.1002/app.25237

[32] Khartamian M., Irani M.: Preparation and characterization of nanosized ZSM-5 zeolite using kaolin and investigation of kaolin content, crystallization time and temperature changes on the size and crystallinity of products. Journal of the Iranian Chemical Society, 6, 187-194 (2009). https://doi.org/10.1007/BF03246519

[33] Jesudoss S. K., Vijaya J. J., Grace A. A., Kennedy A. J., Sivasanker S., Kathirgamanathan P.: Hierarchical ZSM5 zeolite nanosurfaces with high porosity - Structural, morphological and textural investigations. in 'Recent trends in materials science and applications' (ed.: Ebenezar J.) Springer, Berlin, 112-113 (2017).

https://doi.org/10.1007/978-3-319-44890-9 11

[34] Favaro M. M., Branciforti M. C., Bretas R. E. S.: A Xray study of $\beta$-phase and molecular orientation in nucleated and non-nucleated injection molded polypropylene resins. Materials Research, 12, 455-464 (2009). https://doi.org/10.1590/S1516-14392009000400014

[35] Zeng A., Zheng Y., Guo Y., Qiu S., Cheng L.: Effect of tetra-needle-shaped zinc oxide whisker ( $\mathrm{T}-\mathrm{ZnOw}$ ) on mechanical properties and crystallization behavior of isotactic polypropylene. Materials and Design, 34, 691698 (2012).

https://doi.org/10.1016/j.matdes.2011.05.028

[36] Kim D., Jeon S. L., Seo J.: The preparation and characterization of urushiol powders (YPUOH) based on urushiol. Progress in Organic Coatings, 76, 1465-1470 (2013).

https://doi.org/10.1016/j.porgcoat.2013.05.034

[37] Appendini P., Hotchkiss J. H.: Review of antimicrobial food packaging. Innovative Food Science and Emerging Technology, 3, 113-126 (2002). https://doi.org/10.1016/S1466-8564(02)00012-7
[38] Li W., Song G., Tang G., Chu X., Ma S., Liu C.: Morphology, structure and thermal stability of microencapsulated phase change material with copolymer shell. Energy, 36, 785-791 (2011). https://doi.org/10.1016/j.energy.2010.12.041

[39] Qiu X., Song G., Chu X., Li X., Tang G.: Preparation, thermal properties and thermal reliabilities of microencapsulated $n$-octadecane with acrylic-based polymer shells for thermal energy storage. Thermochimica Acta, 551, 136-144 (2013). https://doi.org/10.1016/j.tca.2012.10.027

[40] Shan X. L., Wang J. P., Zhang X. X., Wang X. C.: Formaldehyde-free and thermal resistant microcapsules containing $n$-octadecane. Thermochimica Acta, 494, 104-109 (2009). https://doi.org/10.1016/j.tca.2009.04.026

[41] Beyler C. L., Hirschler M. M.: Thermal decomposition of polymers. in 'SFPE handbook of fire protection engineering' (eds.: Hurley M. J., Gottuk D. T., Hall J. R., Harada K., Kuligowski E. D., Puchovsky M., Torero J. L., Watts J. M., Wieczorek C. J.) Springer, New York, 110-131 (2008).

[42] Jakab E., Várhegyi G., Faix O.: Thermal decomposition of polypropylene in the presence of wood-derived materials. Journal of Analytical and Applied Pyrolysis, 56, 273-285 (2000). https://doi.org/10.1016/S0165-2370(00)00101-7

[43] Arrhenius S.: Über die Dissociationswärme und den Einfluss der Temperatur auf den Dissociationsgrad der Elektrolyte (in German). Wilhelm Engelmann, Leipzig (1889).

[44] Solovyov S., Goldman A.: Mass transport and reactive barriers in packaging. DEStech, Lancaster (2008).

[45] ASTM D882-12: Standard test method for tensile properties of thin plastic sheeting (2012).

[46] ASTM D638-14: Standard test method for tensile properties of plastics (2014). 